\title{
Progress in the total synthesis of inthomycins
}

\author{
Bidyut Kumar Senapati
}

\author{
Review \\ Address: \\ Department of Chemistry, Prabhat Kumar College, Contai, 721404 , \\ India, Tel.: +91 8145207480 \\ Email: \\ Bidyut Kumar Senapati - bsenapati79@gmail.com \\ Keywords: \\ antibiotics; inthomycins; oxazololomycin; Stille coupling; total \\ synthesis
}

\author{
Beilstein J. Org. Chem. 2021, 17, 58-82. \\ https://doi.org/10.3762/bjoc. 17.7 \\ Received: 10 August 2020 \\ Accepted: 03 December 2020 \\ Published: 07 January 2021 \\ Associate Editor: S. Bräse \\ (c) 2021 Senapati; licensee Beilstein-Institut. \\ License and terms: see end of document.
}

\begin{abstract}
The inthomycin family of antibiotics, isolated from Streptomyces strains, are interesting molecules for synthesis due to their characteristic common oxazole polyene chiral allylic $\beta$-hydroxycarbonyl fragments and significant biological activities. The full structural motif of the inthomycins is found in several more complex natural products including the oxazolomycins, 16-methyloxazolomycin, curromycins A and B, and KSM-2690. This review summarises the application of various efforts towards the synthesis of inthomycins and their analogues systematically.
\end{abstract}

\section{Introduction}

Inthomycins, alternatively known as phthoxazolins, are a class of compounds in which a methylene-interrupted oxazolyltriene unit is conjugated to a chiral $\beta$-hydroxycarbonyl center of an amide functionality. Inthomycin A ((+)-1), the first member of the inthomycin family, was isolated by Omura's group from the strain of Streptomyces sp. OM-5714 in 1990 [1]. Then, the following year, Henkel and Zeek had reported the reisolation of inthomycin A ((+)-1) and the first isolation of inthomycin B $((+)-2)$ from the strain of Streptomyces sp. Gö 2, and proved inthomycin $\mathrm{A}((+)-\mathbf{1})$ to be identical with phthoxazolin A $((+)-1)[2]$. Later, the reisolation of inthomycin B ((+)-2) and inthomycin C ((-)-3) was reported by Omura's group in 1995 [3]. Inthomycin A ((+)-1) displays moderate antifungal activity against cellulose-containing Phytophthora parasitica and Phytophthora capsici [4]. Inthomycins were reported to possess many interesting biological properties, which include the specific inhibition of the cellular biosynthesis $[1,4]$, in vitro antimicrobial activity [4,5], and anticancer activity against human prostate cancer cell lines [6,7]. A recent study suggested that the close analogue (+)-11 of inthomycin C was found to exhibit proteasome inhibition activity [8]. The skeletal structures of inthomycins A-C (1-3) are embodied in several other naturally occurring compounds, such as neooxazolomycin (4), oxazolomycins A-C (5, 6) [9-14], curromycins (7) [15], and KSM-2690 (8) [16] (Figure 1). Owing to their various biological activities and characteristic closely related structural motifs, they have generated immense interest among the chemists. Over the past two decades, a wide variety of synthetic strategies have been dedicated towards the synthesis of the inthomycin class of antibiotics. An earlier report on the total synthesis of oxazolomycins provides an overview of the author's synthetic efforts toward neooxazolomycin (4), oxazolomycin A (5a), and 


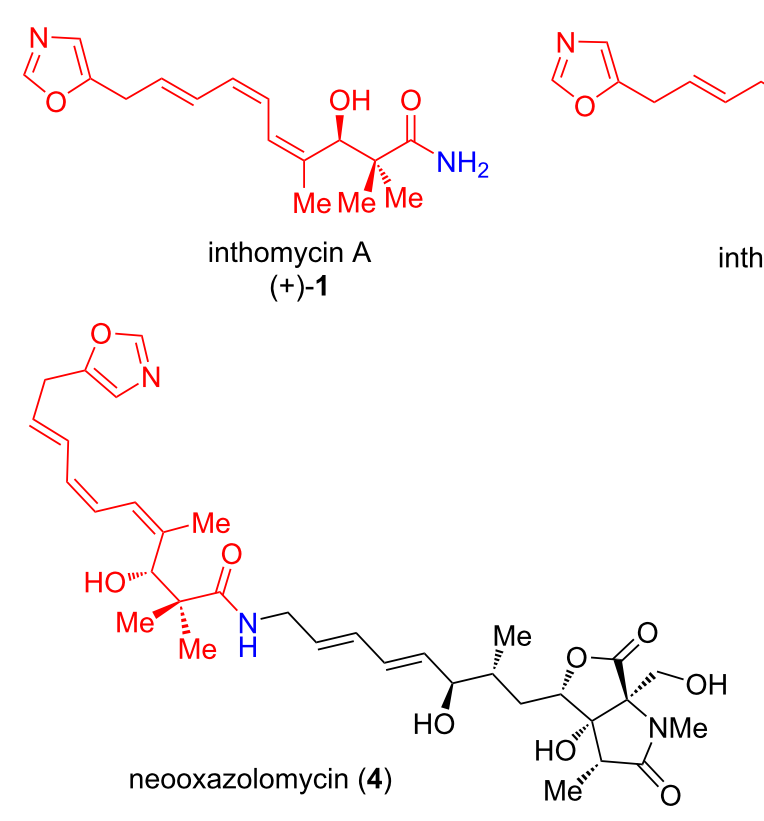<smiles>CC(C)=C(C)C(O)C(C)(C)C(N)=O</smiles>

inthomycin B

$(+)-2$

inthomycin C

$(-)-3$

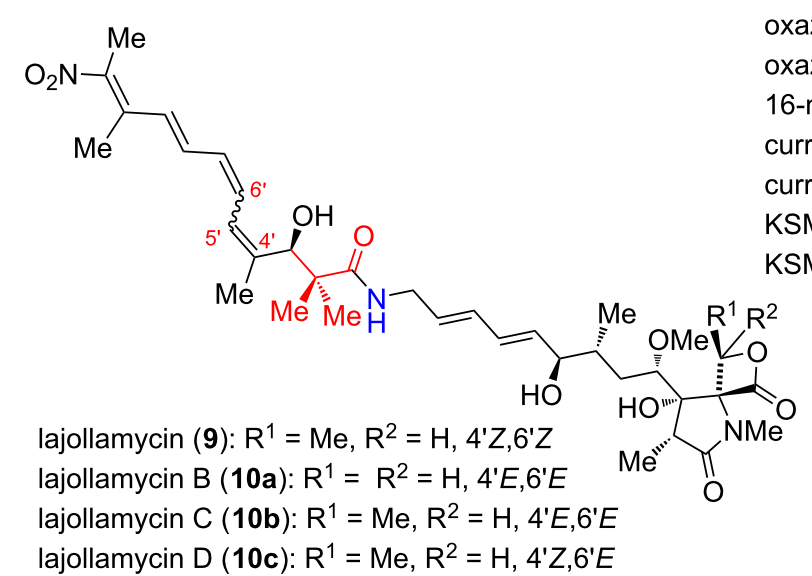

oxazolomycin A (5a): $R^{1}=R^{2}=R^{3}=H ; 4^{\prime} Z, 6^{\prime} Z, 8^{\prime} E$

oxazolomycin $\mathrm{B}(\mathbf{5 b}): \mathrm{R}^{1}=\mathrm{R}^{2}=\mathrm{R}^{3}=\mathrm{H} ; 4^{\prime} E, 6^{\prime} E, 8^{\prime} E$

oxazolomycin C (5c): $\mathrm{R}^{1}=\mathrm{R}^{2}=\mathrm{R}^{3}=\mathrm{H} ; 4^{\prime} Z, 6^{\prime} E, 8^{\prime} E$

16-methyloxazolomycin (6): $\mathrm{R}^{1}=\mathrm{R}^{2}=\mathrm{H}, \mathrm{R}^{3}=\mathrm{Me} ; 4^{\prime} Z, 6^{\prime} Z, 8^{\prime} E$

curromycin A (7a): $\mathrm{R}^{1}=\mathrm{Me}, \mathrm{R}^{2}=\mathrm{H}, \mathrm{R}^{3}=\mathrm{CH}_{2} \mathrm{OMe} ; 4^{\prime} Z, 6^{\prime} Z, 8^{\prime} E$

curromycin $B(7 b): R^{1}=R^{3}=M e, R^{2}=H ; 4^{\prime} Z, 6^{\prime} Z, 8^{\prime} E$

KSM-2690 B (8a): $R^{1}=R^{3}=H, R^{2}=M e ; 4^{\prime} Z, 6^{\prime} Z, 8^{\prime} E$

$\mathrm{KSM}-2690 \mathrm{C}(\mathbf{8 b}): \mathrm{R}^{1}=\mathrm{R}^{3}=\mathrm{H}, \mathrm{R}^{2}=\mathrm{Me} ; 4^{\prime} Z, 6^{\prime} E, 8^{\prime} E$

lajollamycin $D(\mathbf{1 0 c}): R^{1}=M e, R^{2}=H, 4^{\prime} Z, 6^{\prime} E$

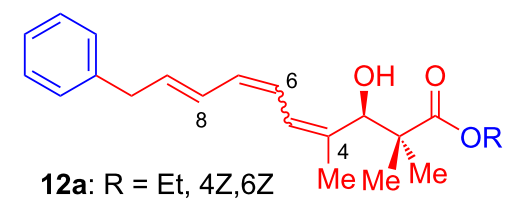

12b: $R=H, 4 Z, 6 Z$

12c: $R=E t, 4 Z, 6 E$

12d: $\mathrm{R}=\mathrm{H}, 4 \mathrm{Z}, 6 E$<smiles>COC(=O)C(C)(C)C(O)/C(C)=C/C=C/C=C/Cc1cnco1</smiles>

13: $\mathrm{R}=\mathrm{Et}, 4 E, 6 E$

$(+)-11$

Figure 1: The inthomycins A-C (1-3) and structurally closely related compounds.

related antibiotics [17]. The recent review of Lee has mainly focused on the application of copper(I) salt and fluoridepromoted Stille coupling reactions in the synthesis of bioactive molecules including inthomycins A-C (1-3) [18]. The present review provides a systematic summary of synthetic strategies for the synthesis of inthomycins and their analogues over the period of 1999 to present.

\section{Rewiew}

\section{Synthesis}

Undoubtedly, the unique skeleton of inthomycins has acted as an inspiration for the development of new synthetic methodolo- gies. Many methods have been developed for the synthesis of inthomycins since their first isolation in 1990 [1]. Most of the reported methods have been directed towards inthomycin $\mathrm{C}$ (3) due to its thermodynamically more favored $4 E, 6 E, 8 E$-triene system. The regiochemical issues of installing the conjugated triene system, which is susceptible to cis-trans isomerization, have been longstanding problems in the area of inthomycins. The problems are more acute for the construction of enantioenriched $\beta$-hydroxycarbonyl units as evident from the recent reports [19-21]. Since the pioneering works of Henaff and Whiting $[19,20]$, several racemic and asymmetric total syntheses of inthomycins A-C (1-3) have been carried out in many 
research groups (Figure 2). However, only four synthetic strategies that lead to the total synthesis of all three members of inthomycins A-C (1-3) are available (Figure 2, route b, d, h, and i) [21-24].

The first racemic synthesis of inthomycin A ((rac)-1), alternatively known as phthoxazolin A, was reported in 1999 [19]. The key steps include i) the synthesis of intermediate dienyl iodide (rac)-20, ii) the synthesis of intermediate oxazole vinylstannane 24, and iii) the Stille coupling between oxazole vinylstannane $\mathbf{2 4}$ and dienyl iodide ( $\mathrm{rac}$ )-20 as the final step. The synthesis began with alcohol $(Z)-\mathbf{1 5 a}$, which was readily prepared in $65 \%$ yield from propargyl alcohol (14) by using a copper(I)-catalyzed methyl Grignard addition followed by in situ iodinolysis. The Swern oxidation of (Z)-15a followed by immediate aldol condensation afforded racemic phenol ester ( $\mathrm{rac}$ )-17 via aldehyde 16. However, several attempts to form enantioenriched aldol fragment 18 using both a chiral auxiliary [25-28] and catalytic asymmetric $[29,30]$ procedures proceeded without success. Therefore, the synthesis of inthomycin A was advanced in the racemic form. Treatment of compound ( $r a c)-17$ with aqueous ammonia gave the corresponding amide ( $\mathrm{rac}$ )-18 in $96 \%$ yield. Heck coupling between ( $r a c)-\mathbf{1 8}$ and vinylboronate pinacol ester [31] using $\mathrm{Pd}\left(\mathrm{PPh}_{3}\right)_{4} / \mathrm{Et}_{3} \mathrm{~N}$ conditions provided stereoselective access to dienylboronate ( $r a c$ )-19a in $43 \%$ yield. A competitive Suzuki coupling was also observed with compound (rac)-19b being isolated in 35\% yield [32-35]. Dienylboronate ( $r a c)-19 a$ was then transformed into dienyl iodide ( $r a c)-20$ by iodine monochloride addition and methoxide-mediated elimination (Scheme 1) [35]. The oxazole vinylstannane 24 was pre-

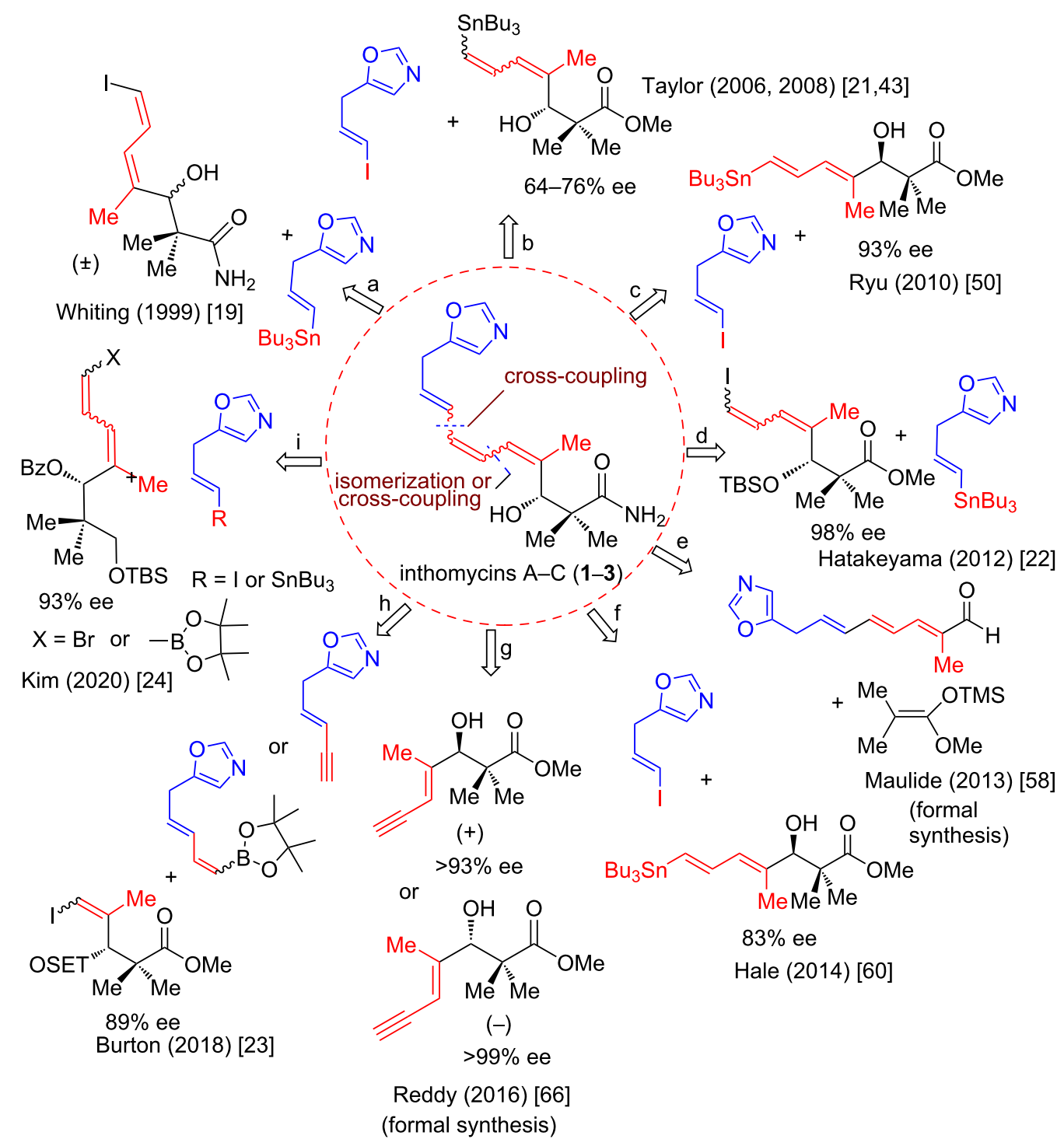

Figure 2: Syntheses of inthomycins A-C (1-3). 
i) synthesis of dienyl iodide (rac)-20:
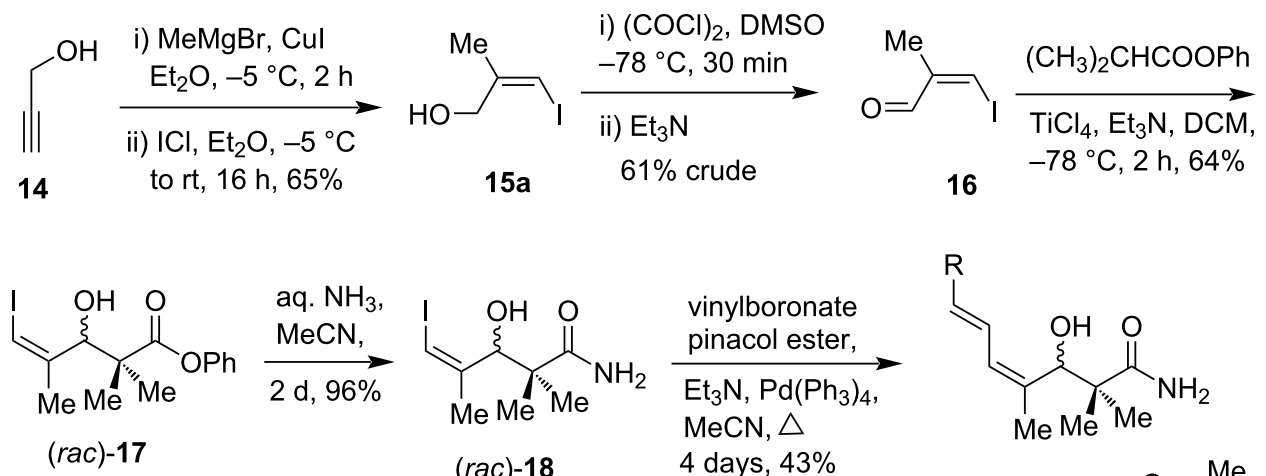

i) $\mathrm{ICl}, \mathrm{DCM}$,

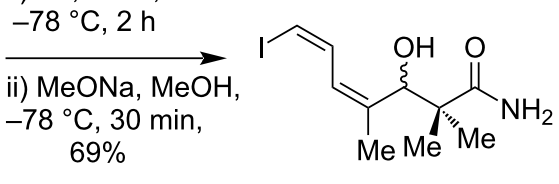

(rac)-20

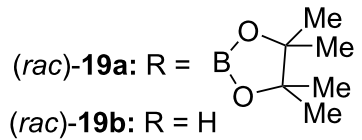

ii) synthesis of oxazole vinylstannane $\mathbf{2 4}$ :

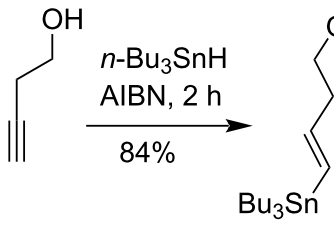

21

22

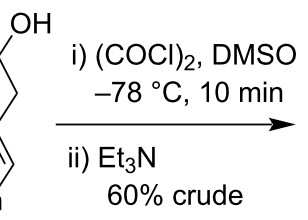<smiles>CCCC[Sn]=CCCC=O</smiles>

23
TosMIC,

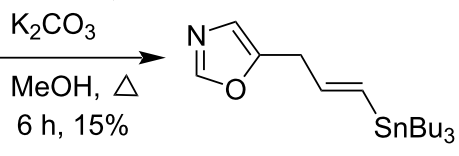

24

iii) Stille coupling:

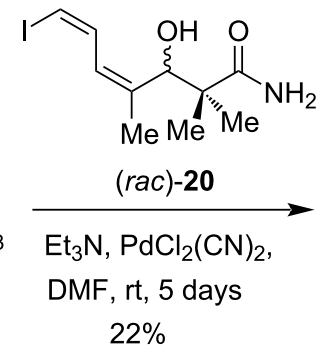

$22 \%$

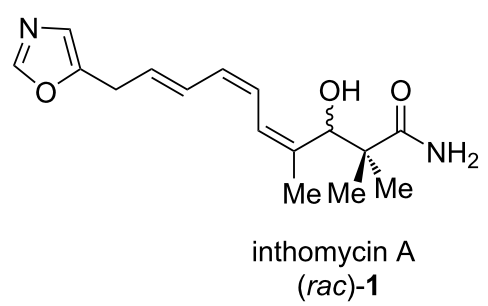

Scheme 1: The first total synthesis of racemic inthomycin A (rac)-1 by Whiting

pared from commercially available butyne 21. The tri- $n$-butyltin hydride addition to 21, followed by Swern oxidation and direct oxazole formation with tosylmethyl isocyanide (TosMIC) gave the fragment 24, which was used immediately for the next step due to its high instability. Finally, the Stille cross-coupling reaction between vinylstannane $\mathbf{2 4}$ and dienyl iodide ( $\mathrm{rac}$ )-20 using $\mathrm{PdCl}_{2}(\mathrm{CN})_{2}$ and triethylamine in DMF produced racemic inthomycin A (or phthoxazolin A) (rac)-1 in 22\% yield (Scheme 1).

Although the overall yield of this route was very low, this work certainly established the basis for the future enantioselective syntheses of inthomycins and related natural products.
In 2002, Moloney et al. described an efficient synthetic route using the Stille coupling reaction as the key step to accomplish the synthesis of phenyl analogues of inthomycins [36]. These triene moieties are a sub-unit of the oxazolomycin class of antibiotics. To prepare the phenyl analogue of racemic inthomycin $\mathrm{C}$ (rac-3), at first, the phosphonate $\mathbf{2 8}$ was prepared using a Claisen condensation of ethyl propionate (25) followed by methylation of $\mathbf{2 6 a}$, treatment with bromine in acetic acid, and then triethyl phosphite. Next, compound 28 was treated with sodium hydride followed by aldehyde 29 [37] to give (E,E)-dienyl stannane 30 in 50\% yield. The key Stille coupling between 30 and vinyl iodide 31, prepared by Takai reaction [38] of phenylacetaldehyde, in presence of $\mathrm{PdCl}_{2}(\mathrm{MeCN})_{2}$ produced $(E, E, E)$ - 
triene 32 in $84 \%$ yield. Finally, $\mathrm{NaBH}_{4}$ reduction of $\mathbf{3 2}$ gave alcohol $(\mathrm{rac})-\mathbf{1 3}$, in which the triene moiety is analogous to inthomycin C ((rac)-3) and oxazolomycin B (5b) (Scheme 2).

After the successful application of the Stille reaction to construct the (E,E,E)-triene system ( $r a c)$-13 in a stereoselective manner, attention was then focused on the development of an analogous strategy towards the $(Z, Z, E)$ - and $(Z, E, E)$-triene systems present in oxazolomycin A (5a) and oxazolomycin $\mathrm{C}$ (5c), respectively. The key steps were i) synthesis of dienyl halides, ii) synthesis of the required vinylstannane and iii) Stille coupling between them (Scheme 3) [39]. The required divinyl halides 36 were prepared, starting from phenylacetaldehyde (33), by using the Takai [38] or Wittig procedures [40] as shown in Scheme $3(68 \%$ of a 3.3:1 mixture of $(E, E) /(Z, E)-\mathbf{3 6 b}$ and $69 \%$ yield of a $8: 1$ mixture of $(Z, E) /(E, E)-\mathbf{3 6 a}$, respectively). Aldehyde 35 was then converted into dibromide 37 using $\mathrm{PPh}_{3} / \mathrm{CBr}_{4}$ followed by stereoselective palladium-catalyzed monoreduction according to the literature available protocol [41] to give vinyl bromide $\mathbf{3 8}$ in $76 \%$ yield $(Z / E$ as 99:1 mixture). Iodide 15a [42] was prepared stereoselectively from propargyl alcohol following the literature procedure, and the free hydroxy group was then protected as its TBDMS ether to produce 39 in $99 \%$ yield.

The metal-halogen exchange of $\mathbf{3 9}$ followed by the $\mathrm{Bu}_{3} \mathrm{SnCl}$ quench in $\mathrm{Et}_{2} \mathrm{O}$ gave the desired stannane $\mathbf{4 0}$ in excellent yield $(90 \%)$. Deprotection of the TBDMS ether of stannane $\mathbf{4 0}$ with tetra- $n$-butylammonium fluoride (TBAF) in THF and then subsequent Swern oxidation of the crude alcohol gave aldehyde 41 in $71 \%$ yield. The aldehyde $\mathbf{4 1}$ was treated with ethyl isobutyrate (42) in the presence of LDA to afford the aldol adduct $(Z)-(r a c)-43$ in the racemic form (92\% yield). The stannane (Z)-(rac)-43 was then subjected to Stille coupling with iodide $(E, E)-36 \mathbf{b}$ (3:1 mixture of stereoisomers, 3 equiv) using $\mathrm{Pd}\left(\mathrm{CH}_{3} \mathrm{CN}\right)_{2} \mathrm{Cl}_{2} / \mathrm{DMF}$ conditions to produce a 3:1 mixture of $(Z, Z, E):(Z, E, E)$ triene products $(\mathrm{rac}) \mathbf{- 1 2 a}$ and $(\mathrm{rac})-\mathbf{1 2 c}$ in $72 \%$ yield after $10 \mathrm{~h}$ reaction time. After optimization, it was found that the above product ratio changed to $1: 1$ when the reaction was allowed to run for $24 \mathrm{~h}$ and only 1.3 equiv of $(E, E)-\mathbf{3 6} \mathbf{b}$ was employed in the Stille coupling. In a similar manner, stannane (Z)-43 coupled with $(Z, E)$-iodide 36a (8:1 ratio of isomers, 1.3 equiv) to produce a $1.2: 1$ mixture of $(Z, Z, E):(Z, E, E)$ triene products $(r a c)-\mathbf{1 2 a}$ and $(r a c)-\mathbf{1 2 c}$ in $74 \%$ yield. The stereoisomers (rac)-12a and (rac)-12c were found to be inseparable by chromatography. The isomerically pure bromide $(Z)-\mathbf{3 8}$ was found to be inert to coupling with vinylstannane ( $\mathrm{rac}$ )-43 under standard Stille conditions. Hydrolysis of a mixture $(3: 1)$ of (rac)-12a and (rac)-12c produced a mixture $(3: 1)$ of the corresponding acids (rac)-12b and (rac)-12d in 70\% yield (Scheme 3). These trienes are analogues of oxazolomycins A (5a) and $\mathrm{C}(\mathbf{5 c})$ and inthomycins $\mathrm{A}(\mathrm{rac}-\mathbf{1})$ and $\mathrm{B}$ (rac-2), respectively.

In 2006, R. J. K. Taylor and co-workers reported the first total synthesis of inthomycin B ((+)-2) using a Stille coupling of a stannyl-diene with an oxazole vinyl iodide unit followed by a Kiyooka ketene acetal/amino acid-derived oxazaborolidinone

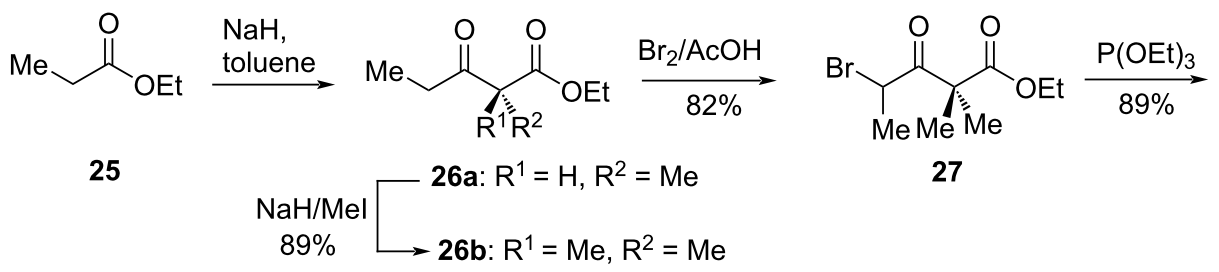<smiles>CCOC(=O)C(C)(C)C(=O)C(C)(C)C(=O)OCC</smiles>

28

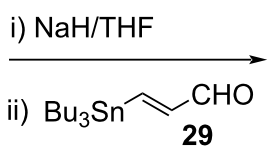

$50 \%$<smiles>CCOC(=O)C(C)(C)C(=O)/C(C)=C/C=C/[Sn](C)(C)C</smiles>

30 i) $\underset{\mathrm{PdCl}_{2}(\mathrm{MeCN})_{2}}{\stackrel{\mathrm{Ph}}{\longrightarrow}}$ $84 \%$<smiles>CCOC(=O)C(C)(C)C(=O)/C(C)=C/C=C/C=C/Cc1ccccc1</smiles><smiles>CCOC(=O)C(C)(C)[C@H](O)/C(C)=C/C=C/C=C/Cc1ccccc1</smiles> 
i) Synthesis of the dienyl halides $\mathbf{3 6}$ and $\mathbf{3 8}$ :

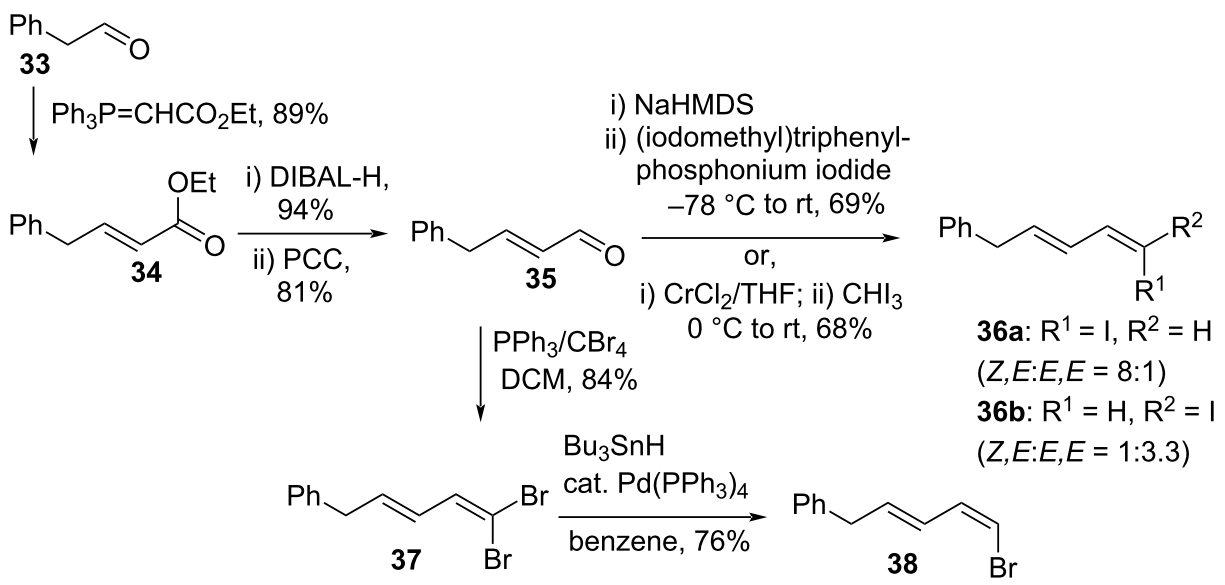

ii) synthesis of the vinylstannane fragment (rac)-43:

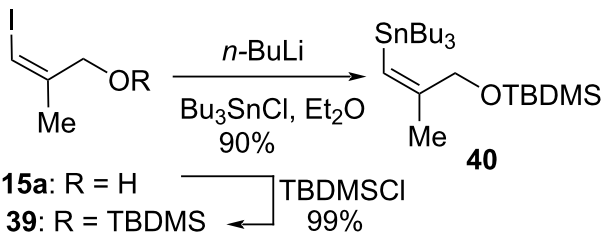

iii) Stille coupling between ( $(r a c)-43$ and $\mathbf{3 6}$ or $\mathbf{3 8}$ :

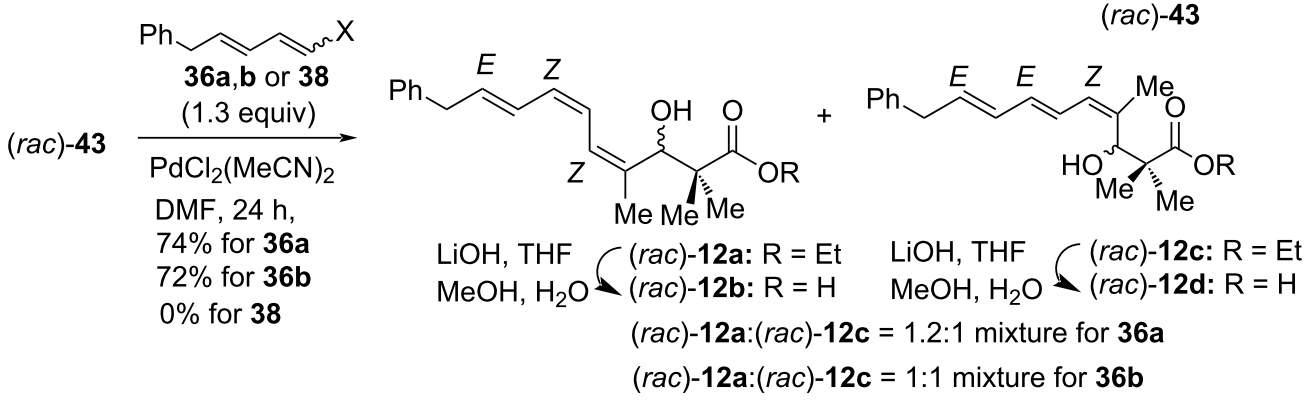

Scheme 3: Moloney's synthesis of phenyl analogues of inthomycins A (rac-1) and B (rac-2).

procedure as its cornerstones (Scheme 4) [43]. In the beginning, oxazole 45 was prepared in good yield $(86 \%)$ by treating ethyl glyoxylate with tosyl methyl isocyanate (TosMIC) in the presence of $\mathrm{K}_{2} \mathrm{CO}_{3}$ at $80{ }^{\circ} \mathrm{C}$ [44]. The reduction of the ethyl ester of 45 followed by NBS treatment gave unstable bromide 46 [45], which was immediately coupled to (E)-1,2-bis(tri-n-butylstannyl)ethene (47) using catalytic $\mathrm{Pd}_{2} \mathrm{dba}_{3}$ in refluxing THF to produce iodide 48 in $46 \%$ yield. The coupling partner $(Z, E)-(+)-54$ was prepared enatioselectively from the known (E)-3-(tributylstannyl)propenal (49) [46] using a four-step sequence. Treatment of $\mathbf{4 9}$ with the Still-Gennari bis-trifluoroethoxy phosphonate reagent $\mathbf{5 0}$ proceeded stereoselectively to give ester 51 in excellent yield (94\%). Subsequent DIBAL-H reduction of ester $\mathbf{5 1}$ followed by tetrapropylammonium perruthenate (TPAP) oxidation afforded aldehyde $(Z, E)-\mathbf{5 2}$ as a single isomer in $83 \%$ yield over two steps. The asymmetric aldol reaction aldehyde $(Z, E)-\mathbf{5 2}$ with silyl ketene acetal $\mathbf{5 3}$ in the presence of oxazaborolidinone derived from $N$-tosyl-Lvaline and $\mathrm{BH}_{3}$.THF generated the desired alcohol $(Z, E)-(+)-54$ in $74 \%$ yield and $64 \%$ ee. Next, a wide range of catalysts/conditions were screened for the crucial Stille coupling between iodide 48 and $(Z, E)-(+)-54$ to overcome the problems of isomerization of the $(Z, E, E)$-triene unit of the desired products. Finally, $\mathrm{PdCl}_{2}\left(\mathrm{CH}_{3} \mathrm{CN}\right)_{2}(1 \mathrm{~mol} \%)$ in DMF was found to smoothly deliver the required triene (+)-55 in quantitative yield. After many unsuccessful attempts of direct conversion of methyl ester (+)-55 into the corresponding primary amide, acetylation of acid 56a followed by acid chloride formation of acetate 56b and in situ ammonium hydroxide treatment was found to be fruitful to produce inthomycin B (+)-2 in reason- 


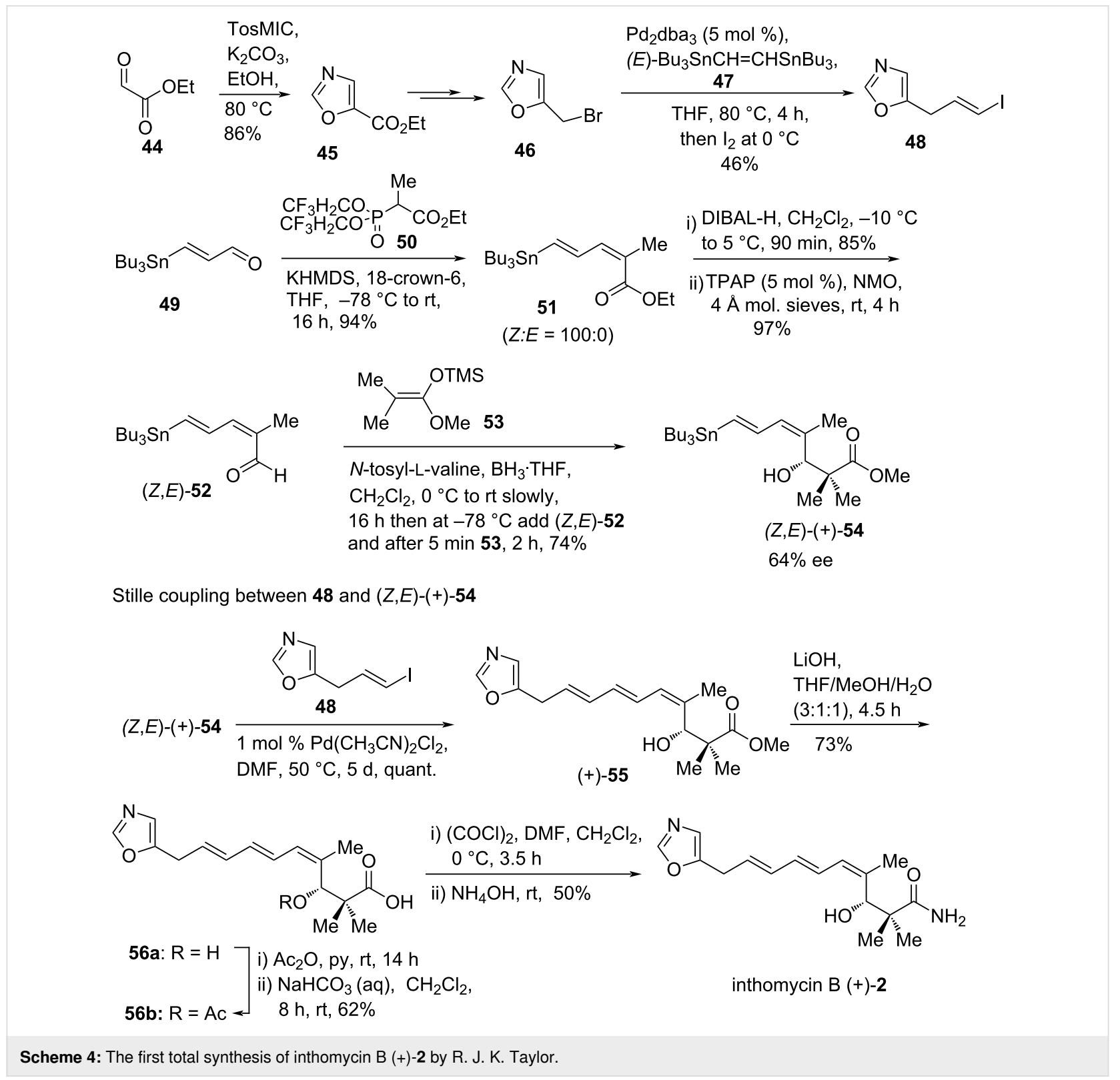

able yield (Scheme 4). This synthetic route introduced the chiral entry to any member of the inthomycin family for the first time.

In 2008, R. J. K. Taylor and co-workers described a unified synthetic route to the inthomycin family [21]. The developed procedure has been utilized successfully to prepare racemic inthomycin A ((rac)-1) and inthomycin C ((+)-3) (Scheme 5 and Scheme 6). The previously reported procedure $[20,45]$ was modified to improve the yield of inthomycin A ( $(\mathrm{rac})-\mathbf{1})$ by replacing the Stille coupling partners. The required $(Z)-3$-(tributylstannyl)propenal (57) was easily accomplished by $\mathrm{LiAlH}_{4}$ reduction of propargyl alcohol (14) and then transmetallation with $\mathrm{Bu}_{3} \mathrm{SnCl}$ followed by oxidation of the resulting alcohol using the Ley-Griffith TPAP procedure $[47,48]$. Treatment of aldehyde 57 with the Ando phenoxy phosphonate 58a [49] gave the desired $(Z, Z)$-diene $\mathbf{5 9}$ as the major product $(\mathbf{5 9} / \mathbf{6 0}=87: 13)$. DIBAL-H reduction of $\mathbf{5 9}$ allowed the isolation of $(Z, Z)$ isomeric alcohol followed by subsequent oxidation produced aldehyde $(Z, Z)-61$. After extensive unsuccessful efforts to produce enantiopure aldol fragment $(Z, Z)-62$ using the $N$-tosylL-valine-derived oxazaborolidinone, the racemic synthesis of $(Z, Z)-(r a c)-62$ was achieved by utilizing the lithium enolate of methyl isobutyrate. Stille coupling of $(Z, Z)-(\mathrm{rac})-\mathbf{6 2}$ with vinyl iodide 48 in the presence of $\mathrm{Pd}\left(\mathrm{CH}_{3} \mathrm{CN}\right)_{2} \mathrm{Cl}_{2}$ in DMF proceeded smoothly to give the corresponding ester (triene isomerization was less than $20 \%$ during coupling), which was then converted into acid derivative ( $r a c)-63$ by saponification. Finally, the acid derivative ( $r a c)-63$ was subjected to undergo acetylation, acid 


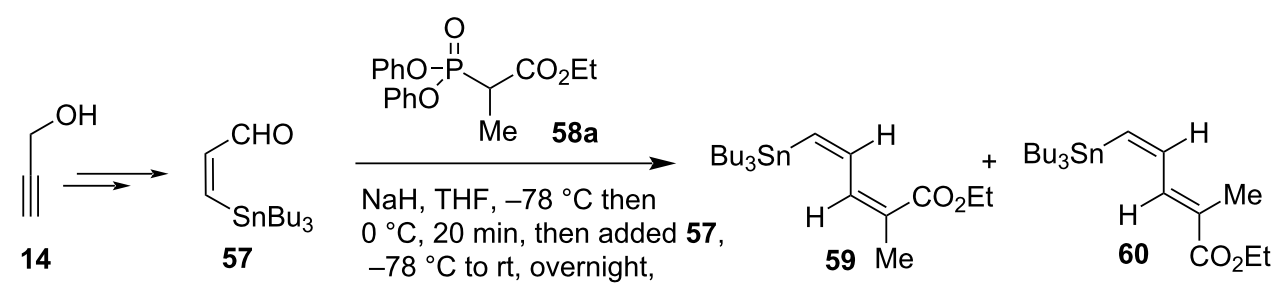

$-78{ }^{\circ} \mathrm{C}$ to rt, overnight, $80 \%(59 / 60=87: 13)$

i) DIBAL-H, DCM, $\quad \mathrm{Me}_{2} \mathrm{CHCO}_{2} \mathrm{Me}$ $-35^{\circ} \mathrm{C}$ to $0{ }^{\circ} \mathrm{C}$, LDA, THF, $-78^{\circ} \mathrm{C}$,<smiles>CCOC(=O)/C(C)=C/C=C\[SnH2]C(C)(C)C</smiles>
$\underset{\text { ii) TPAP, NMO, } 4 \AA}{2 \mathrm{~h}, 68 \%}$ mol. sieves, $\mathrm{DCM}$.
$0^{\circ} \mathrm{C}, 2 \mathrm{~h}$, quant. $\mathrm{Bu}_{3} \mathrm{Sn}$

\begin{tabular}{|c|c|}
\hline & $25 \mathrm{~min}$ \\
\hline $\mathrm{Me}_{\mathrm{Me}}^{\mathrm{CH}}$ & $\begin{array}{l}\text { then add } 61 \text { at } \\
-78^{\circ} \mathrm{C}, 2 \mathrm{~h}\end{array}$ \\
\hline 61 & \\
\hline
\end{tabular}<smiles>C/C(=C/C=C\C=C\Cc1cnco1)[C@@H](O)C(C)(C)C(=O)O</smiles><smiles>I/C=C/Cc1cnco1</smiles>

i) $5 \mathrm{~mol} \% \mathrm{Pd}\left(\mathrm{CH}_{3} \mathrm{CN}\right)_{2} \mathrm{Cl}_{2}$, DMF, rt, $5 \mathrm{~h}, 77 \%$

ii) $\mathrm{LiOH} \cdot \mathrm{H}_{2} \mathrm{O}, \mathrm{THF}, \mathrm{MeOH}$,<smiles>COC(=O)C(C)(C)[C@H](O)/C(C)=C\C=C/[SnH2]C(C)(C)C</smiles>
i) $\mathrm{Ac}_{2} \mathrm{O}, \mathrm{py}, \mathrm{rt}, 20 \mathrm{~h}$,
then $\mathrm{NaHCO}_{3}(\mathrm{aq})$,
$\mathrm{DCM}, \mathrm{rt}, 2 \mathrm{~h}$, quant. ii) $\mathrm{SOCl}_{2}$, DMF, DCM, $0{ }^{\circ} \mathrm{C}$ to $\mathrm{rt}, 2.5 \mathrm{~h}$, then $\mathrm{NH}_{4} \mathrm{OH}, \mathrm{rt}, 1 \mathrm{~h}, 70 \%$

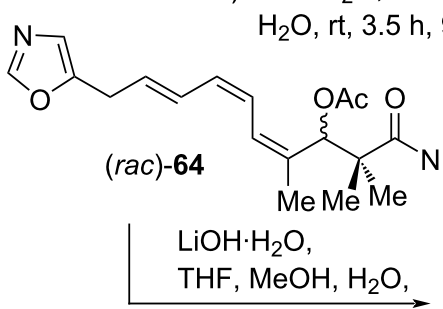

rt, 1 h, $92 \%$<smiles>C/C(=C/C=C\C=C\Cc1cnco1)[C@@H](O)C(C)(C)C(N)=O</smiles>

inthomycin A (rac)-1

Scheme 5: R. J. K. Taylor's total synthesis of racemic inthomycin A (rac)-1.

chloride formation, and quenching with ammonium hydroxide to produce amide derivative ( $r a c)-64$ in $70 \%$ yield. Finally, saponification of acetate ( $\mathrm{rac}$-64 using lithium hydroxide gave racemic inthomycin $\mathrm{A}((\mathrm{rac})-1)$ in $14 \%$ overall yield (Scheme 5).

The total synthesis of inthomycin $\mathrm{C}((+)-3)$ was achieved by using a Stille coupling between $(E, E)-$,67 and vinyl iodide 48 followed by directed asymmetric aldol reaction under Mukaiyama-Kiyooka aldol reaction conditions (Scheme 6) Initially, (E)-3-(tributylstannyl)propenal (65) was converted into $(E, E)$-diene $\mathbf{6 6}(E / Z=19: 1$, separable) using the standard $(E)$-selective Horner-Wadsworth-Emmons (HWE) reaction. DIBAL-H reduction of ester $\mathbf{6 6}$ followed by $\mathrm{MnO}_{2}$ oxidation produced aldehyde (E,E)-67 stereoselectively. Unfortunately, attempted enantioselective aldol reactions of $(E, E)-67$ with silylketene acetal $\mathbf{5 3}$ using $N$-tosyl-L-valine-derived oxazaborolidinone $\mathbf{6 8}$ gave a negligible amount of the required dienylstan- nane $(E, E)-69$ with a significant amount of destannylated product 70. The destannylation process could not be prevented even after a range of reaction conditions were tested. Thus, this approach was revised and the key Stille coupling was carried out before the introduction of the asymmetric aldol fragment (Scheme 6). Therefore, the key Stille coupling of aldehyde $(E, E)-67$ with vinyl iodide 48 in the presence of $\mathrm{PdCl}_{2}\left(\mathrm{CH}_{3} \mathrm{CN}\right)_{2}$ gave $(E, E, E)$-trienal 71 in $74 \%$ yield. The trienal 71 underwent asymmetric aldol reaction in the presence of oxazaborolidinone derivative $\mathbf{6 8}$ and silyl ketene acetal $\mathbf{5 3}$ to produce the required $\alpha$-hydroxy ester (+)-11 in 50\% yield and $76 \%$ ee $((R)$-stereochemistry of the major enantiomer). A competitive reduction of $\mathbf{7 1}$ was also observed to produce alcohol $\mathbf{7 2}$ in $43 \%$ yield. Finally, hydrolysis of the ester (+)-11 followed by hexafluorophosphate azabenzotriazole tetramethyl uranium (HATU)-mediated coupling with ammonia gave inthomycin $\mathrm{C}((+)-3)$ in $33 \%$ yield, containing inseparable tetramethylurea as byproduct (ca. 20\%). 


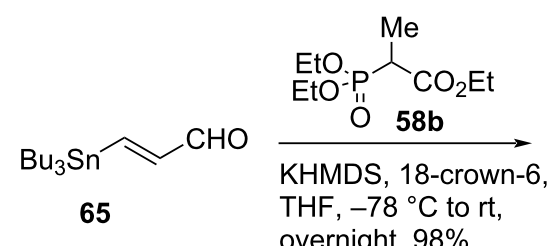

65 overnight, $98 \%$<smiles>CCOC(=O)/C(C)=C/C=C/[SbH2]C(C)(C)C</smiles>

66 i) DIBAL-H, $\mathrm{CH}_{2} \mathrm{Cl}_{2}$, $-10^{\circ} \mathrm{C}$ to $\mathrm{rt}, 3 \mathrm{~h}$, quant.

ii) $\mathrm{MnO}_{2}, \mathrm{CH}_{2} \mathrm{Cl}_{2}$, rt $2 \mathrm{~d}$, quant.<smiles>CCC(C)C=CC=C(C)C=O</smiles>

$(E, E)-67$<smiles>[13CH3]/C=C/Cc1cnco1</smiles>

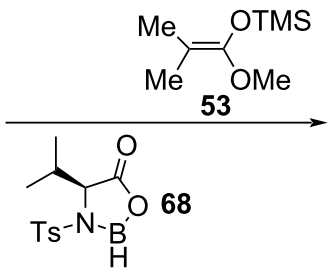

$\mathrm{CH}_{2} \mathrm{Cl}_{2}, 0{ }^{\circ} \mathrm{C}, 5 \mathrm{~min}$ then $\mathrm{rt}, 25 \mathrm{~min}$ then $-78{ }^{\circ} \mathrm{C}$ $E, E-67$, and $68,3 \mathrm{~h}$<smiles>COC(=O)C(C)(C)[C@H](O)/C(C)=C/C=C/[SnH2]C(C)(C)C</smiles>

(E,E)-69 (trace)<smiles>C=C/C=C(\C)[C@@H](O)C(C)(C)C(=O)OC</smiles>

70 (major)<smiles>CC(C=O)=CC=CC=CCc1cnco1</smiles><smiles>CC(C)=C(C)O[Mg]</smiles>

$\mathrm{N}$-tosyl-L-valine, $\mathrm{BH}_{3} \cdot \mathrm{THF}$, $\mathrm{CH}_{2} \mathrm{Cl}_{2}, 0^{\circ} \mathrm{C}, 20 \mathrm{~min}$,<smiles>CC(=CC=CC=CCc1cnco1)CO</smiles>
$30 \mathrm{~min}$ then $-78^{\circ} \mathrm{C}$, $2 \mathrm{~h}, 71$ and 53<smiles>CC(=CC=CC=CCc1cnco1)[C@@H](O)C(C)(C)C(N)=O</smiles>
$(+)-3$

+ inseparable tetramethylurea (ca. $20 \%$ )

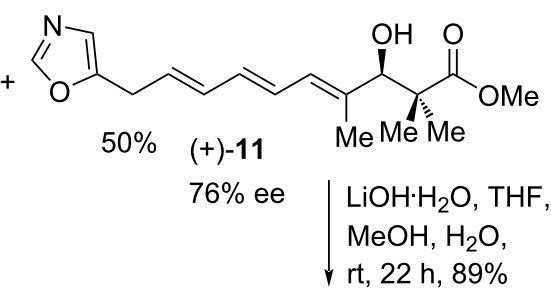

HATU,<smiles>CCN[PH2+]C(C)(N)C(F)(F)Cl</smiles>
rt, $15 \mathrm{~h}$, $33 \%$.<smiles>CC(=CC=CC=CCc1cnco1)C(O)C(C)(C)C(=O)O</smiles>

$(+)-73$
In 2010, Senapati, Ryu et al. [50] described the first total synthesis of naturally occurring inthomycin $\mathrm{C}((-)-3)$ in excellent yield and enantiopurity by employing a cationic oxazaborolidinium-catalyzed asymmetric Mukaiyama aldol reaction and Stille coupling as the key steps (Scheme 7). Treatment of compound 75 with tetra- $n$-butylammonium fluoride (TBAF) in THF at $-78{ }^{\circ} \mathrm{C}$ and the resulting solution was carefully allowed to warm to $0{ }^{\circ} \mathrm{C}$ to give the desired alcohol $(E, E)-(-)-69$ in $86 \%$ yield and $93 \%$ ee with only trace amounts of the corresponding destannylated product, a major disadvantage of R. J. K. Taylor's synthesis of (+)-inthomycin C, ((+)-3, see Scheme 6, compound 70) [21]. Next, the key Stille coupling reaction of dienylstannane (E,E)-(-)-69 with oxazole vinyl iodide 48 using $\mathrm{Pd}\left(\mathrm{PPh}_{3}\right)_{4} / \mathrm{CsF} / \mathrm{CuI}$ conditions $[51,52]$ gave ester $(+)-\mathbf{1 1}$ in $85 \%$ yield. The ester $(+)-11$ was then hydrolyzed with lithium hydroxide to give the corresponding acid (+)-73 in 90\% yield. The transformation of acid (+)-73 to acetate $(+)-76$ using acetic anhydride in pyridine followed by acid activation with oxalyl chloride and then in situ treatment with $28 \%$ ammonium hydroxide afforded amide (-)-77 in $90 \%$ yield. Finally, deacetylation of (-)-77 using lithium hydroxide produced (-)-inthomycin $\mathrm{C}((-)-3)$ in $80 \%$ yield with high enantiopurity (Scheme 7).

In 2012, Hatakeyama and co-workers reported a unified strategy for the asymmetric total syntheses of inthomycin A $((+)-1)$, inthomycin B ((+)-2), and inthomycin C ((-)-3), starting with an organocatalytic asymmetric $[2+2]$ cycloaddi- 

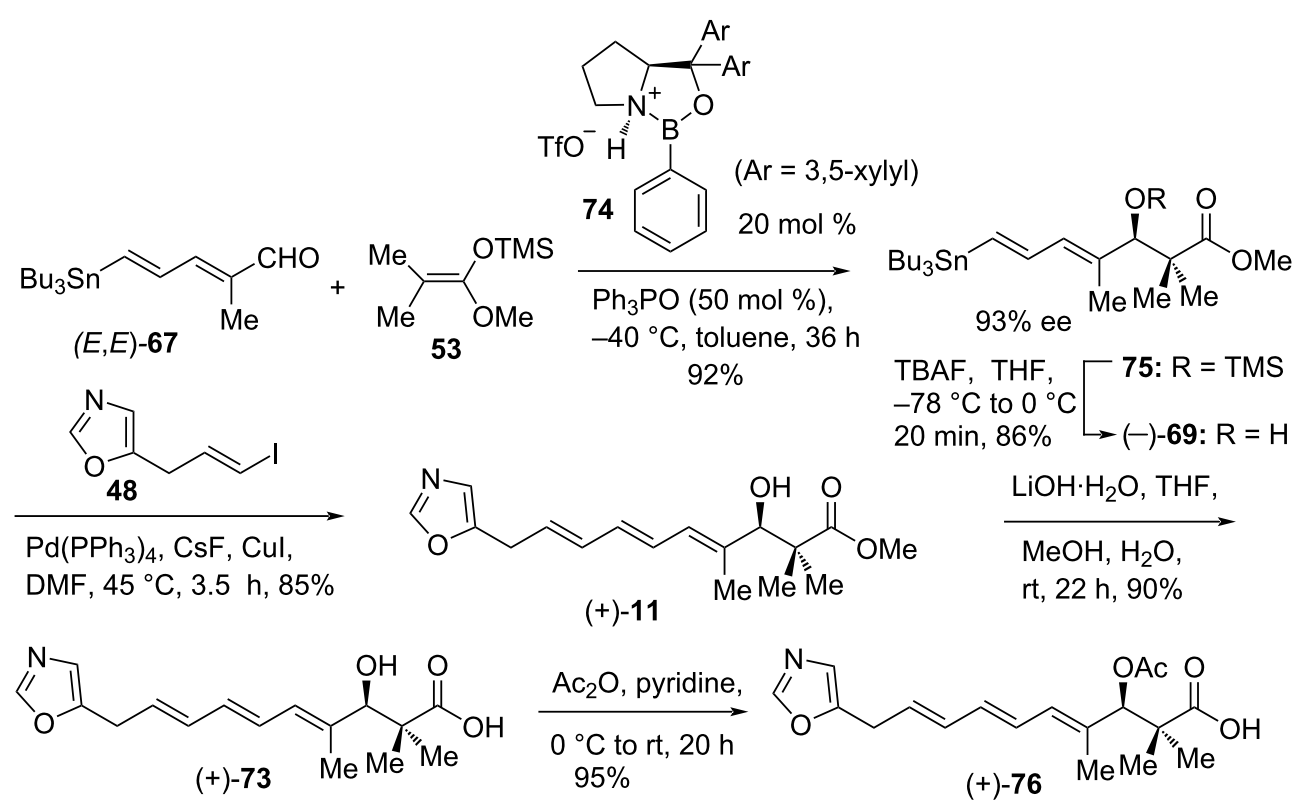

$(\mathrm{COCl})_{2}$, DMF (1 drop) $\mathrm{CH}_{2} \mathrm{Cl}_{2}, 0{ }^{\circ} \mathrm{C}$ to rt, $3.5 \mathrm{~h}$

then excess $\mathrm{NH}_{4} \mathrm{OH}(28 \%)$ rt, $12 \mathrm{~h}, 90 \%$<smiles>CC(=O)OC(/C(C)=C/C=C/C=C/Cc1cnco1)C(C)(C)C(N)=O</smiles>
$(-)-77$

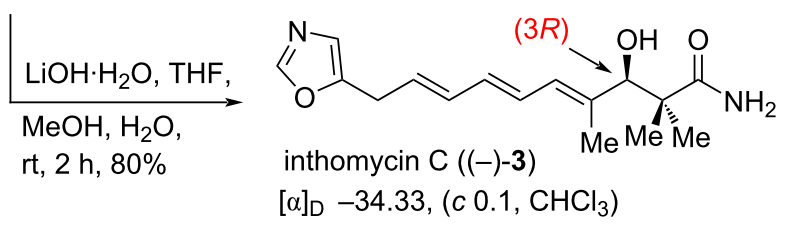

Scheme 7: The first total synthesis of naturally occurring inthomycin C ((-)-3) by Ryu et al.

tion reaction of an aldehyde and a ketene followed by their isomerization-free Stille coupling with $(E)$-5-(3-(tributylstannyl)allyl)oxazole (Schemes 8-10) [22]. In this synthesis, the enantiopure $\beta$-lactone (+)-79a was synthezised from $(Z)$-aldehyde 78 and propionyl chloride according to Nelson's method [53-55] using quinidine TMS ether (TMSQD), $\mathrm{LiClO}_{4}$, and Hünig's base. The aldehyde $(Z)-\mathbf{7 8}$ was obtained from propargyl alcohol 14 via $(Z)$-iodo alcohol 15a. The $\beta$-lactone $(+)-79 a$ was converted to enantioenriched vinyl iodides $(+)-84$ and 85a separately. Thus, methanolysis of (+)-79a provided $(-)-80 a$ which was methylated using methyl iodide and lithium diisopropylamide (LDA) to produce (-)-81a in $84 \%$ yield. Desilylation of (-)-81a followed by tert-butyldimethylsilyl (TBS) protection of (-)-82a gave ester (+)-83. Compound (+)-83 was converted to $(Z, Z)-(+)-84$ by using iodination and a diimide reduction as reported previously [56]. Similarly, the treatment of (+)-83 with in situ-generated Schwartz's reagent from zirconocene dichloride and DIBAL-H followed by iodine to produce an inseparable 6:1 mixture of $(Z, E)$-iododiene $\mathbf{8 5} \mathbf{a}$ and its 6-iodo-isomer $\mathbf{8 5 b}$ in $82 \%$ yield (Scheme 8 ).
The vinyl iodide $(Z, Z)-(+)-84$ was coupled to stannane $\mathbf{2 4}$, using the Mee-Lee-Baldwin (MLB) protocol [51,52], to afford (+)-86. Finally, removal of TBS protection followed by functional group modifications, compound (+)-86 was transformed into inthomycin A $((+)-\mathbf{1})$. Similarly, the coupling between vinyl iodide $\mathbf{8 5 a}$ and stannane $\mathbf{2 4}$ produced triene (+)-88. Subsequently, compound (+)-55 was transformed into inthomycin B ((+)-2, Scheme 9).

For the synthesis of inthomycin C ((-)-3), Hatakeyama et al. prepared $(E)$-aldehyde 78 starting from propargyl alcohol 14 via (E)-iodo alcohol $\mathbf{1 5 b}$. Treatment of $(E)-\mathbf{7 8}$ with propionyl chloride, $\mathrm{LiClO}_{4}$, and diisopropylethylamine in the presence of quinidine TMS ether (TMSQD) according to Nelson's procedures [53-55] provided the enantioenriched $\beta$-lactone (-)-79b in $85 \%$ yield. The desired terminal acetylene (-)-82b was synthesized from $\beta$-lactone (-)-79b following a three-step sequence as shown in Scheme 10. Subsequent stannylation followed by iodination converted compound (-)-82b to an inseparable 7:1 mixture of $(E, E)$-iododiene $(+)-\mathbf{8 9} \mathbf{a}$, and its 6-iodo isomer $\mathbf{8 9 b}$ in 

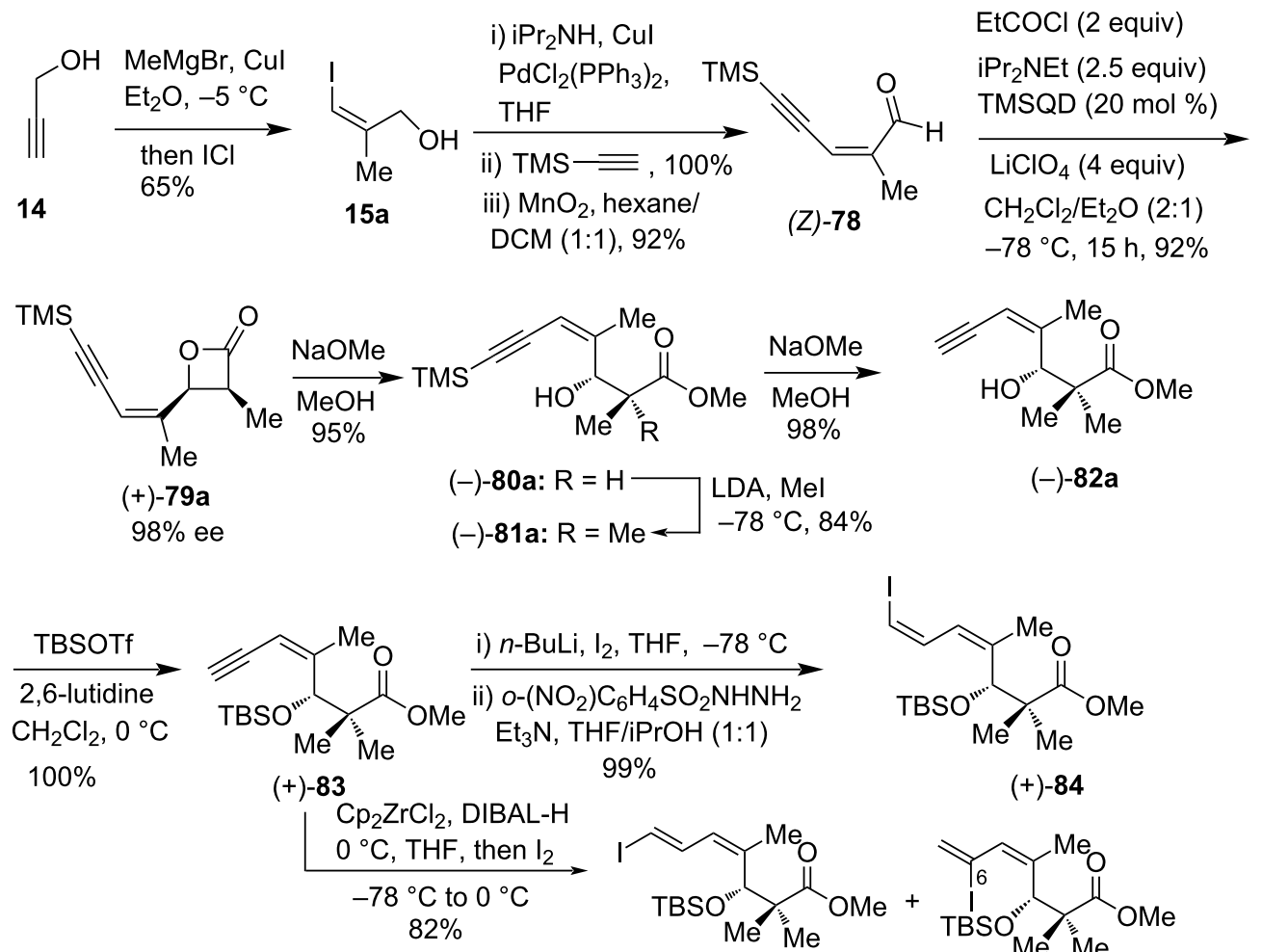

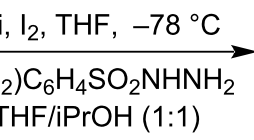
$99 \%$

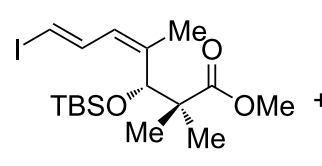

$85 a$<smiles>COC(=O)C(C)(C)[C@@H](/C(C)=C\C=C/I)C(C)C</smiles>

$(+)-84$<smiles>COC(=O)C(O[Na])C(C)(C)C(=O)OC</smiles>

(+)-84

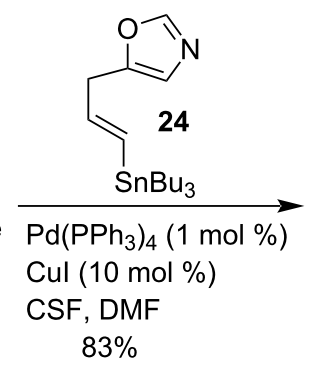<smiles>NCO</smiles>

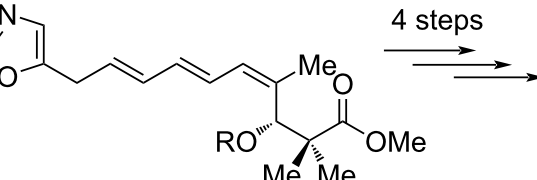
$(+)-2$ $[\alpha]_{\mathrm{D}}^{21}+46.8$ (c 1.25, $\mathrm{CHCl}_{3}$ )
(+)-1

$[\alpha]_{\mathrm{D}}^{21}+37.3$ (c $0.62, \mathrm{CHCl}_{3}$ )
$\overrightarrow{\mathrm{Pd}\left(\mathrm{PPh}_{3}\right)_{4}(1 \mathrm{~mol} \%)}$

Cul $(10 \mathrm{~mol} \%)$

CsF, DMF

$57 \%$

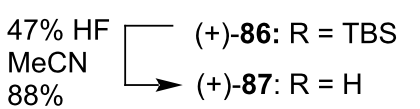<smiles>CC#CC#CC</smiles>

$+)-87: \mathrm{R}=\mathrm{H}$<smiles>COC(=O)[C@](C)(O[AsH3])[C@H](O[AsH3])/C(C)=C\C=C\I</smiles>

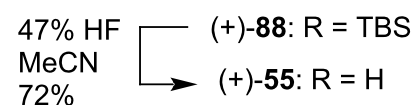

Scheme 9: Hatakeyama's total synthesis of inthomycin A (+)-1 and inthomycin B (+)-2. 
$60 \%$ yield. Compound (+)-89a was then subjected to Stille coupling with oxazole vinylstannane 24 using $\mathrm{Pd}\left(\mathrm{PPh}_{3}\right)_{4}, \mathrm{CuI}$, and $\mathrm{CsF}$ in DMF at room temperature to give $(E, E, E)-(+)-\mathbf{1 1}$ in $79 \%$ yield. This compound was then transformed successfully to (inthomycin C ((-)-3) in a four-step sequence (Scheme 10).

The difference in Hatakeyama's approach to inthomycin C $((-)-3)$ is the polarity reversal of the Stille coupling components relative to that from R. J. K. Taylor's and Ryu's study (see Scheme 6 and Scheme 7). Hatakeyama et al. reported the specific rotation of their synthetic inthomycin $\mathrm{C}((-)-3)$ as $[\alpha]_{\mathrm{D}}$ $-41.5\left(c 0.10, \mathrm{CHCl}_{3}\right)$ [22] whereas R. J. K. Taylor and Ryu reported the values as $[\alpha]_{\mathrm{D}}+25.9\left(c 0.27, \mathrm{CHCl}_{3}\right.$, containing ca. $20 \%$ inseparable tetramethylurea) $[21]$ and $[\alpha]_{D}-34.33(c$ $0.10, \mathrm{CHCl}_{3}$ ) [50], respectively. The specific rotation values provided by Hatakeyama and Ryu's groups were consistent with respect to their synthetic (3R)-inthomycin $\mathrm{C}((-)-3)$. Although, this $[\alpha]_{D}$ measurement was found to be in the opposite sign to the value reported by the group of R. J. K. Taylor. Therefore, the absolute configuration assignment of $(3 R)$ inthomycin C ((-)-3) as described by the Ryu and Hatakeyama groups contradicted with that of the R. J. K. Taylor group. Later, the groups of Hale and Hatakeyama tried hard to eliminate all the contradictions regarding the specific rotation values of inthomycin $\mathrm{C}$ and securely assigned the (3R)-configuration for inthomycin C ((-)-3) [57].

In the synthetic studies towards racemic inthomycin C ( $(r a c)-3)$, Maulide and co-workers investigated the stereoselective synthesis of halocyclobutenes and their ring-opening reactions

i) preparation of $(E, E)$-iododiene $(+)-89$ a
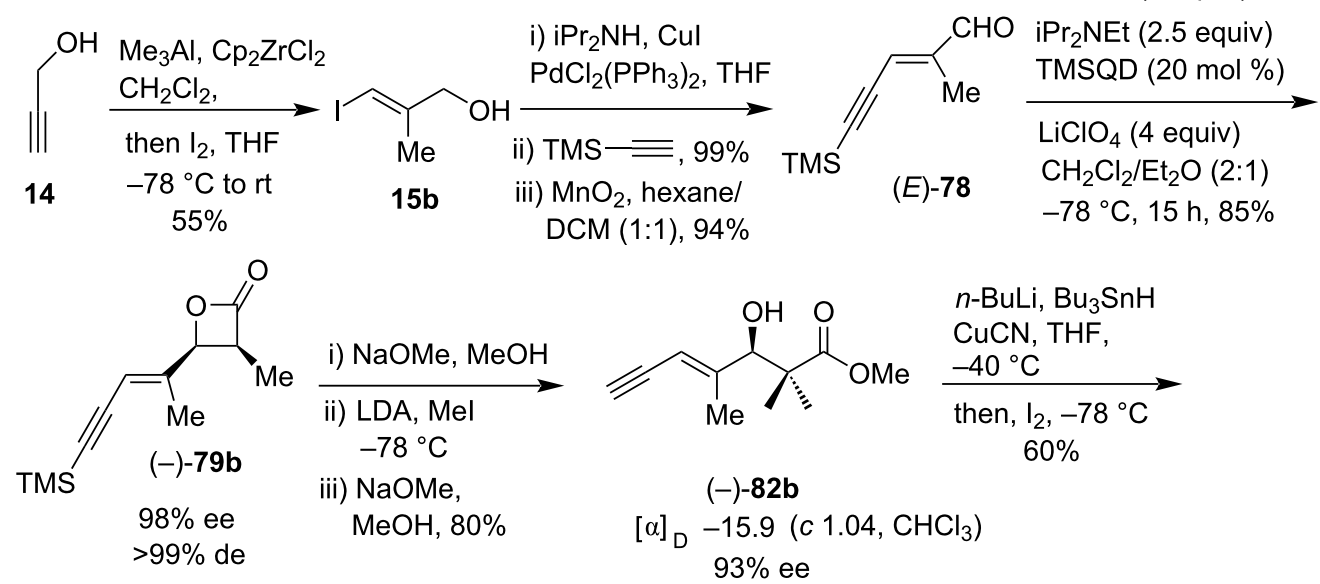

$n$-BuLi, $\mathrm{Bu}_{3} \mathrm{SnH}$

CuCN, THF,

$\underset{\text { then, } \mathrm{I}_{2},-78^{\circ} \mathrm{C}}{\longrightarrow}$

$60 \%$

$>99 \%$ de<smiles>C=C(I)/C=C(\C)C(O)C(C)(C)C(=O)OC</smiles>

$(+)-89 a \quad 7: 1 \quad 89 b$

ii) Stille coupling between (+)-89a and 24

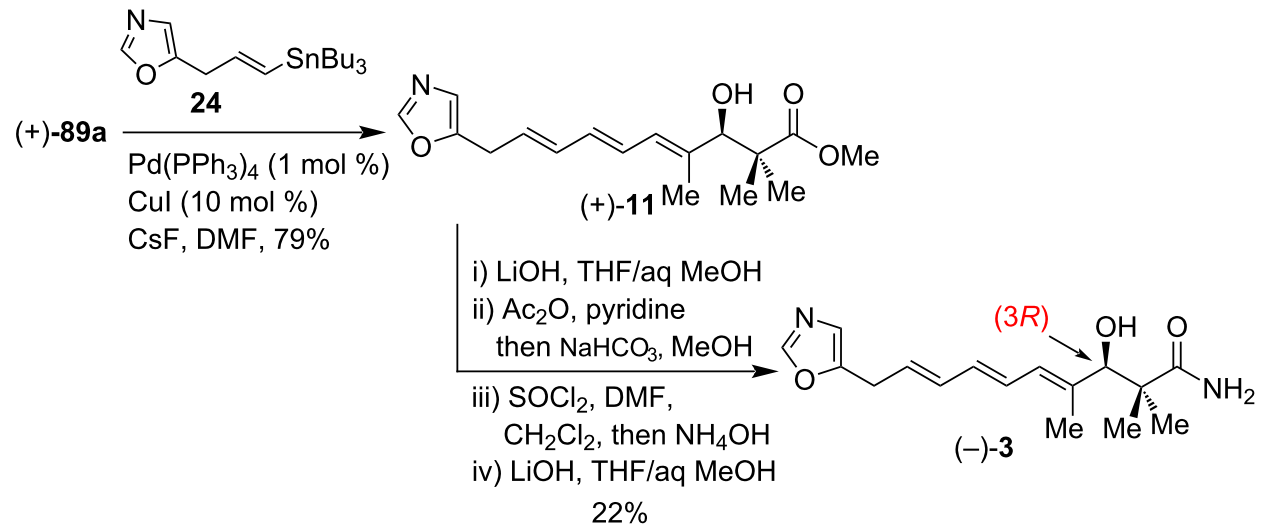

Scheme 10: Hatakeyama's total synthesis of inthomycin C ((-)-3). 
(Scheme 11) [58]. The synthesis commenced with the smooth ring opening of the methyl-substituted lactone 90 using lithium bromide, which gave a single trans-cyclobutenyl bromide $\mathbf{9 1}$. Then, the bromocyclobutene 91 was submitted to further amide coupling and $4 \pi$ electrocyclic ring opening to produce 2-methyl-5-bromodienoic amide $\mathbf{9 2}$ stereoselectively in 73\% yield over three steps. Stille cross-coupling of $\mathbf{9 2}$ with vinylstannane $\mathbf{2 4}$ followed by DIBAL-H reduction produced aldehyde 71, which then underwent an organocatalytic Mukaiyama aldol reaction with silylketene acetal $\mathbf{5 3}$ to produce racemic (E,E,E)-triene (rac)-11 in 50\% yield [59]. Since triene (rac)-11 has been previously transformed into inthomycin $\mathrm{C}$, this study demonstrated the formal synthesis of racemic inthomycin $\mathrm{C}$ $(($ rac $)-3)[21,22,43,50]$.

An interesting application of the O-directed free radical hydrostannation reaction was demonstrated by Hale et al. in the total synthesis of inthomycin $\mathrm{C}((+)-\mathbf{3})$ and it was also claimed that the previous $(3 S)$-stereochemical revision of inthomycin $\mathrm{C}$ $((+)-3)$ by the groups of Ryu [50] and Hatakeyama [22] was found to be invalid based on their modified Mosher ester preparation and optical rotation evidence [60]. The synthetic route was designed in such a way that intercept both Ryu's intermediate (+)-69 [50] and Hatakeyama's intermediate (+)-82b [22] (Scheme 12 and Scheme 13). In this approach, the asymmetric alkylation of 96 with alkyne 95 under Carreira's conditions [6163] afforded (-)-98 in $82 \%$ yield ( $83 \%$ ee). Subsequent free radical hydrostannation on (-)-98 produced (+)-99 as the major product of a $46: 1$ mixture of $(Z / E)-\alpha$-stannylated geometric isomers. The purified vinylstannane (+)-99 underwent iodination stereoselectively with excess $N$-iodosuccinimide to give $(-)-100$, which was then transformed into (-)-101 using a threestep sequence. Upon iodination of (-)-101 produced iodide (+)-102 in excellent yield. Deiodination of (+)-102 followed by regioselective dihydroxylation with Sharpless' AD mix- $\beta$ reagent $[64,65]$ provided diol $(-)-\mathbf{1 0 3}$ as a mixture of stereoisomers. Significantly, the diol (-)-103 was transformed into both enantiopure fragments (+)-69 and (+)-82b successfully (Scheme 12).

The observed specific rotation value for $(+)-69$ was found to be $+5.3^{\circ}\left(c 1.11, \mathrm{CHCl}_{3}\right)$ [60], which contradict the previous results $\left([\alpha]_{\mathrm{D}}-17.5^{\circ}\left(c 0.12, \mathrm{CHCl}_{3}\right)\right.$ [50]. At this stage, Hale and co-workers had concluded that (+)-69 must have (3R)stereochemistry and they had completed a formal total synthesis of the Zeeck-Taylor [2,21] stereostructure for inthomycin C $((+)-3)$. To remove any doubt, Stille cross-coupling of $\mathbf{4 8}$ with (+)-69 was performed under Ryu's conditions [50] to give the desired product $(+)-\mathbf{1 1}$ with a 5.9:1 mixture of inseparable stereoisomeric triene components. Compound (+)-11 was then

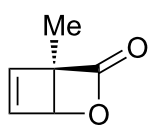

90
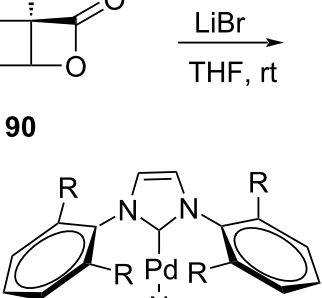

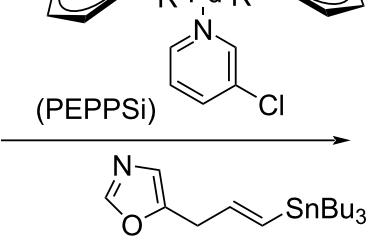

24

DMF, $50^{\circ} \mathrm{C}, 72 \%$

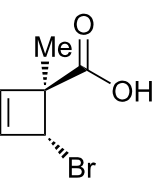

91 i) $(\mathrm{COCl})_{2}$

then $\mathrm{NH}(\mathrm{OMe}) \mathrm{Me} \cdot \mathrm{HCl}$

$\mathrm{DCM}, 0^{\circ} \mathrm{C}$

ii) $\mu$-wave, THF

$73 \%$ yield over 3 steps<smiles>CON(C)C(=O)/C(C)=C/C=C/Br</smiles>

92<smiles>[R2]C(=O)/C([Y6])=C/C=C/C=C/Cc1cnco1</smiles>

93: $\mathrm{XR}=\mathrm{NMe}(\mathrm{OMe})$

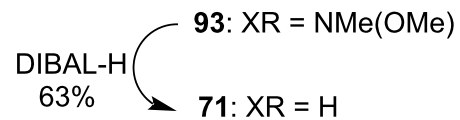

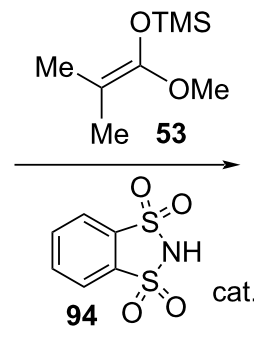

DCM, rt, then TBAF

$\mathrm{THF}, 0^{\circ} \mathrm{C}, 50 \%$<smiles>COC(=O)C(C)(C)C(O)/C(C)=C/C=C/C=C/Cc1cnco1</smiles>

(rac)-11 formal synthesis

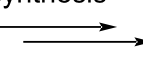

(rac)-3 


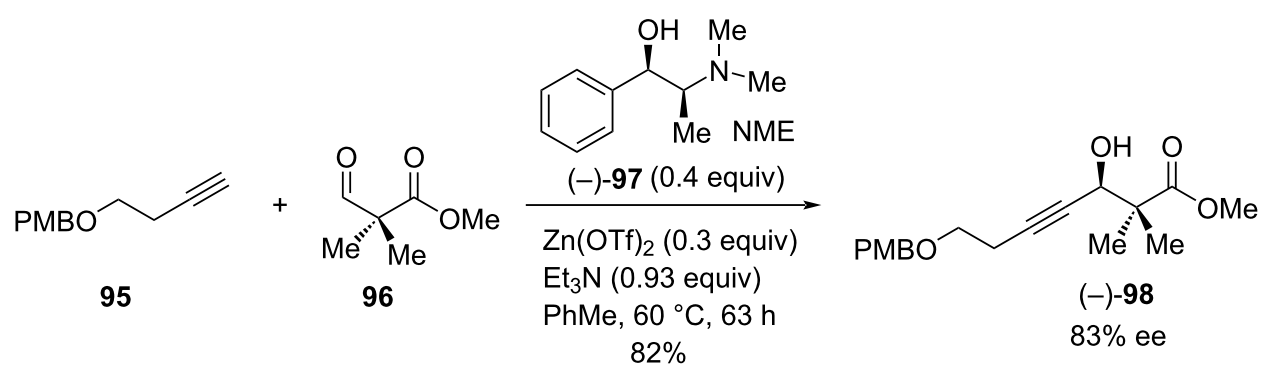
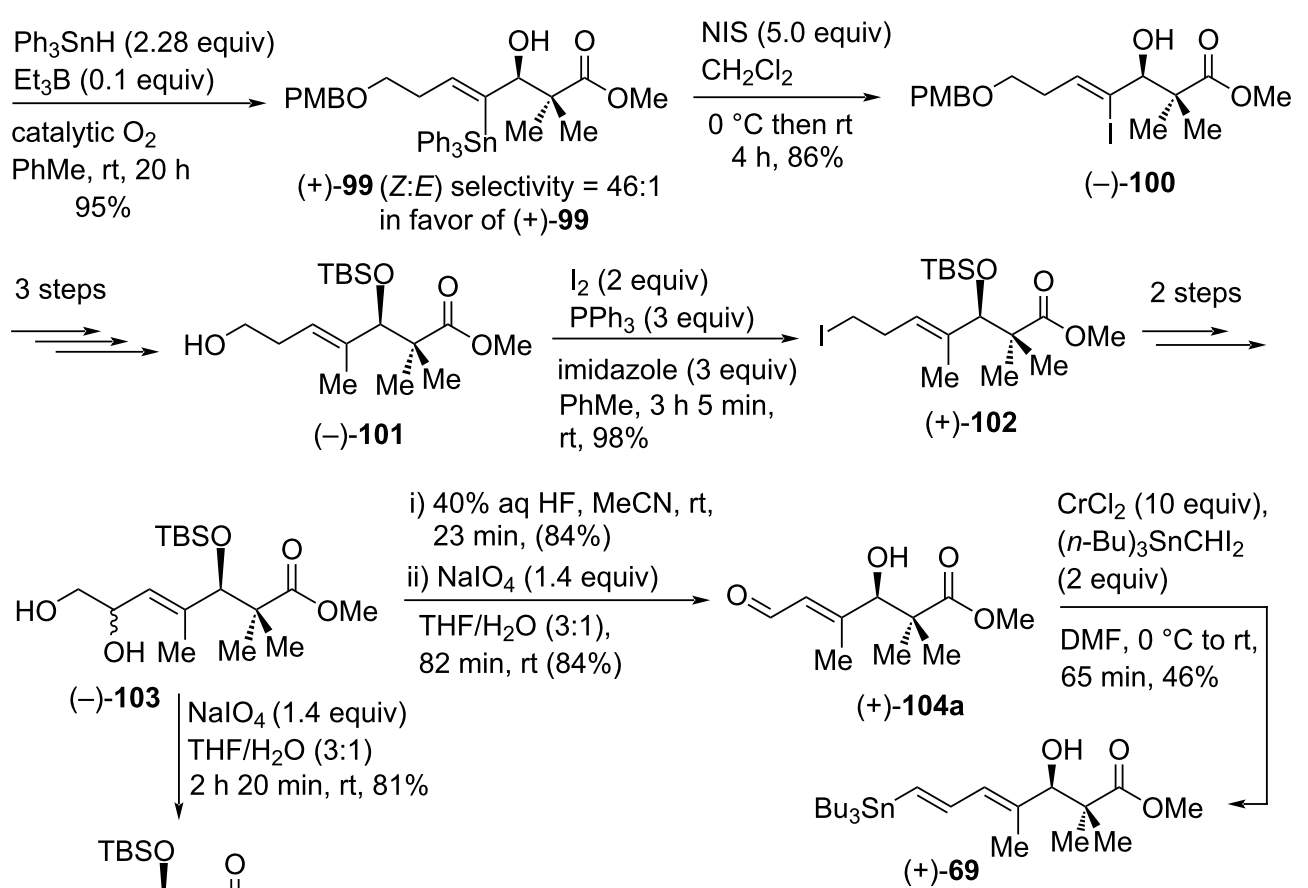<smiles>COC(=O)C(OC(C)(C)C)C(C)(C)C(C)=CC=O</smiles>

$[\alpha]_{D}+5.3\left(c 1.11, \mathrm{CHCl}_{3}\right), 83 \%$ ee

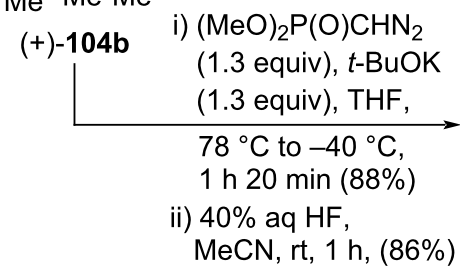<smiles>C#C/C=C(\C)C(O)C(C)(C)C(=O)OC</smiles>

$(+)-82 b$

$[\alpha]_{D}+12.6\left(c \quad 0.71, \mathrm{CHCl}_{3}\right), 83 \%$ ee

Scheme 12: Hale's synthesis of dienylstannane (+)-69 and enyne (+)-82b intermediates.

smoothly converted into a 5.9:1 mixture of inthomycin $\mathrm{C}$ $((+)-3)$ and another isomer via a three-step sequence (Scheme 13).

Unfortunately, further purification of $(+)-3$ could not be achieved at the end and the $[\alpha]_{\mathrm{D}}$ value obtained for the 5.9:1 mixture of inthomycin $\mathrm{C}((+)-3)$ was $-8.4\left(c 1.0, \mathrm{CHCl}_{3}\right)$. The observed $[\alpha]_{\mathrm{D}}$ value was lower in magnitude compared to that of Ryu's [50] and Hatakeyama's synthesis [22] and opposite in sign with R. J. K. Taylor's synthesis [21]. On the other hand, the specific rotation value of the newly synthesized fragment (+)-82b (see Scheme 12) had a similar magnitude but opposite in sign to that reported by Hatakeyama previously [22]. Thus, the absolute stereochemical assignment of enyne (+)-82 b was revised as $(3 R)$, which contradicted Hatakeyama's postulated $(3 R)$ configuration of enyne (-)-82b (Scheme 10) [22]. Hence, this new total synthesis has claimed to reinstate the originally formulated Zeeck-Taylor $(3 R)$-stereostructure [2,21] for inthomycin C ((+)-3), R. J. K. Taylor's total synthesis (Scheme 6) and disputes Ryu and Hatakeyama's (3S)-stereochemical revision of inthomycin C (+)-3 (See Scheme 7 and Scheme 10). 


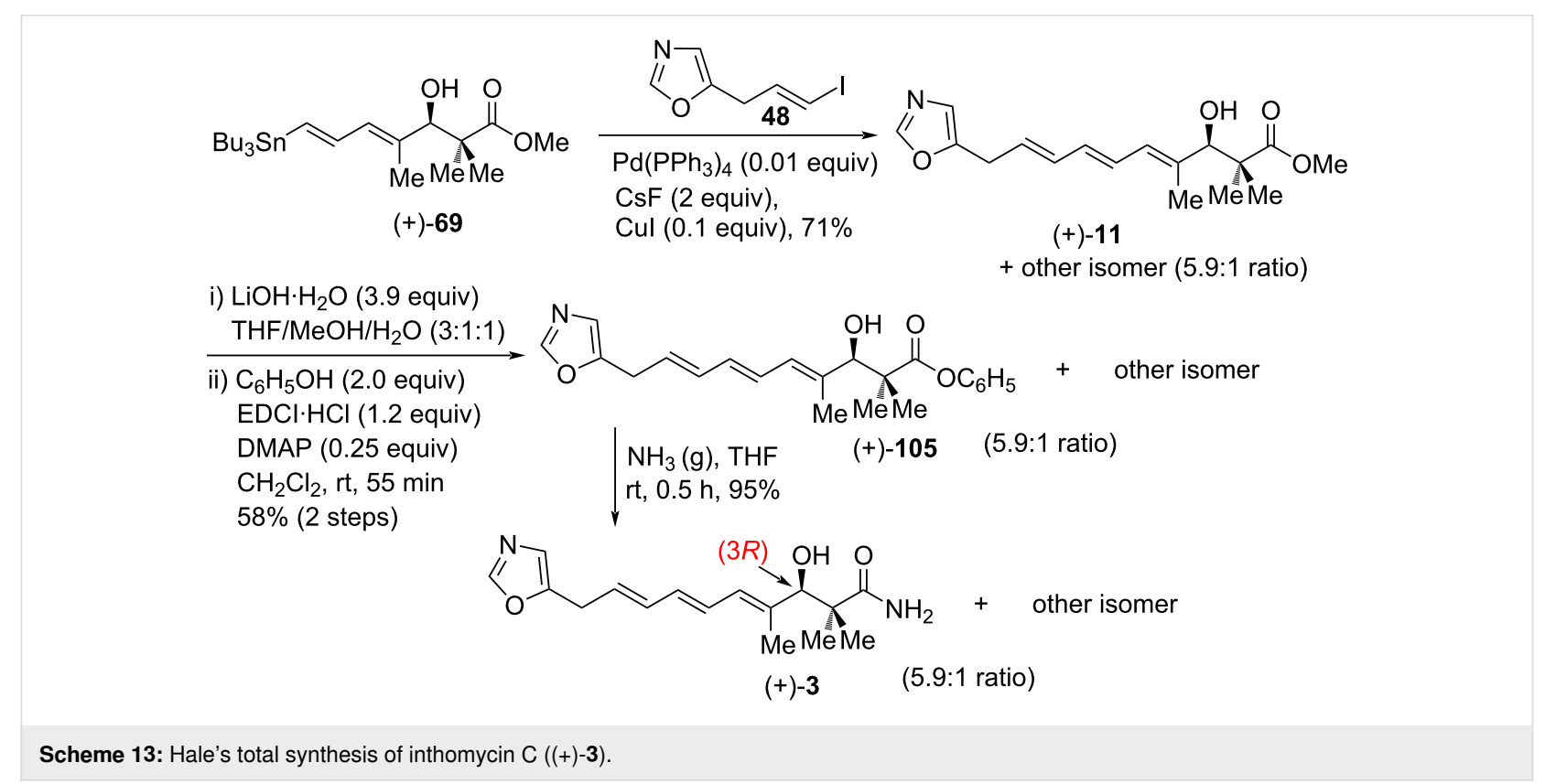

Soon after, a subsequent collaboration between the Hale and Hatakeyama groups demonstrated that inthomycin $\mathrm{C}((-)-3)$ has $(3 R)$ - and not (3S)-stereochemistry [57]. Careful reappraisal of the previously published work $[21,22,50,60]$ now strongly recommends that the R. J. K. Taylor, Ryu, Hatakeyama, and Hale teams all have synthesized (3R)-inthomycin C ((-)-3), despite their discrepant $[\alpha]_{D}$ values. All the disputes and anomalies regarding the specific rotation values of the common intermediate $82 \mathrm{~b}$ and the synthetic ( $3 R$ )-inthomycin $\mathrm{C}$ described by Hale and others were finally resolved in this work. Subsequently, the Hatakeyama team converted their authentic (+)-82 into the $(R)$ - and $(S)$-MTPA Mosher esters which provided wellmatched NMR data to Hale's previous synthesis [60]. Upon further purification using flash chromatography, the Hatakeyama team re-examined their $[\alpha]_{\mathrm{D}}$ data for the authentic $(3 R)$-enynol 82b which had been stored in their laboratory and it was found that $(3 R)-\mathbf{8 2 b}$ had a $[\alpha]_{\mathrm{D}}$ of $+12.2\left(c 0.95, \mathrm{CHCl}_{3}\right)$. This specific rotation was well consistent with the +12.6 ( $c$ $0.71, \mathrm{CHCl}_{3}$ ) value as reported by the Hale group previously for the same enynol 82b (Scheme 12). Then, the Hatakeyama and Hale groups worked together to resolve the disagreement regarding $[\alpha]_{D}$ values of $(3 R)-\mathbf{8 2} \mathbf{b}$ that had been published by both groups. As a part of their collaborative work, the Hale group collected the purified ( $3 R$ )-enynol $\mathbf{8 2 b}$ from the Hatakeyama team and recorded its specific rotation value as $+14.4\left(c 0.58, \mathrm{CHCl}_{3}\right)$. Following this correct $[\alpha]_{\mathrm{D}}$ measurement, both groups concurred that they had prepared the same $(3 R)$-enynol 82b and indeed completed the total synthesis of (3R)-inthomycin C ((-)-3) (Scheme 10 and Scheme 12). Also, the Hatakeyama group freshly resynthesized inthomycin $\mathrm{C}$ from their remaining sample of the $(+)-(3 R)-\mathbf{8 2} \mathbf{b}$ and subsequent $[\alpha]_{\mathrm{D}}$ measurement provided a value of -7.9 (c $0.33, \mathrm{CHCl}_{3}$ ) (Scheme 14). Although this new value was much lower in magnitude compared to previous reports $\left(-41.5\left(c 0.1, \mathrm{CHCl}_{3}\right)\right)$ [22] by the same group, it was much closer to Hale's report [60] for a 5.9:1 mixture of inthomycin $\mathrm{C}\left(-8.4\left(c 1.0, \mathrm{CHCl}_{3}\right)\right)$ (see Scheme 13). Meanwhile, the Hale group transformed the resynthesized inthomycin $\mathrm{C}((-)-3)$ into the corresponding $(R)$-and $(S)$-MTPA ester derivatives $\mathbf{1 0 6}$ and $\mathbf{1 0 7}$, respectively (Scheme 14). Based on the corrected specific rotation value of inthomycin $\mathrm{C}((-)-3)$ and re-investigation of their $(R)$ - and $(S)$ MTPA esters, Hale and Hatakeyama jointly concluded that Ryu and others had indeed synthesized (3R)-inthomycin C ((-)-3).

Two years later, Reddy and co-workers accomplished enantiospecific formal syntheses of both inthomycins $\mathrm{C}((+)-3)$ and inthomycin C ((-)-3) using Hatakeyama's enynol intermediate 82b (Scheme 15) [66]. The synthesis commenced with the benzylation of $(R)$-pantolactone 108a to produce (+)-109a in $85 \%$ yield. Next, treatment of (+)-109a with $N, O$-dimethylhydroxylamine hydrochloride, and an excess of $\mathrm{MeMgBr}$ followed by immediate TBS ether formation produced (+)-110a in $82 \%$ yield over 2 steps. Wittig olefination of $(+)-110 a$ with phosphonate 111 furnished the desired $(E)-(+)-112 a$, which was then converted into Hatakeyama's enynol (-)-82b using a fourstep sequence to complete the formal synthesis of inthomycin $\mathrm{C}$ $((+)-3)$. The spectroscopic data as well as the $[\alpha]_{D}$ value of the present compound (-)-82b were well-matched with that published previously $[22,60]$. Similarly, $(S)$-pantolactone $\mathbf{1 0 8 b}$ was transformed into enyol (+)-82b by following the same procedures as described for (-)-82b to accomplish the formal synthesis of inthomycin $\mathrm{C}((-)-\mathbf{3})$. 
<smiles>C#C/C=C(\C)C(O)C(C)(C)C(=O)OC</smiles>

$(+)-82 b$

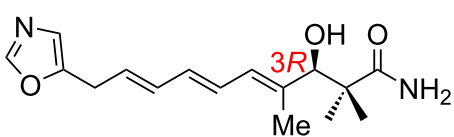

(3R)-inthomycin C (-)-3

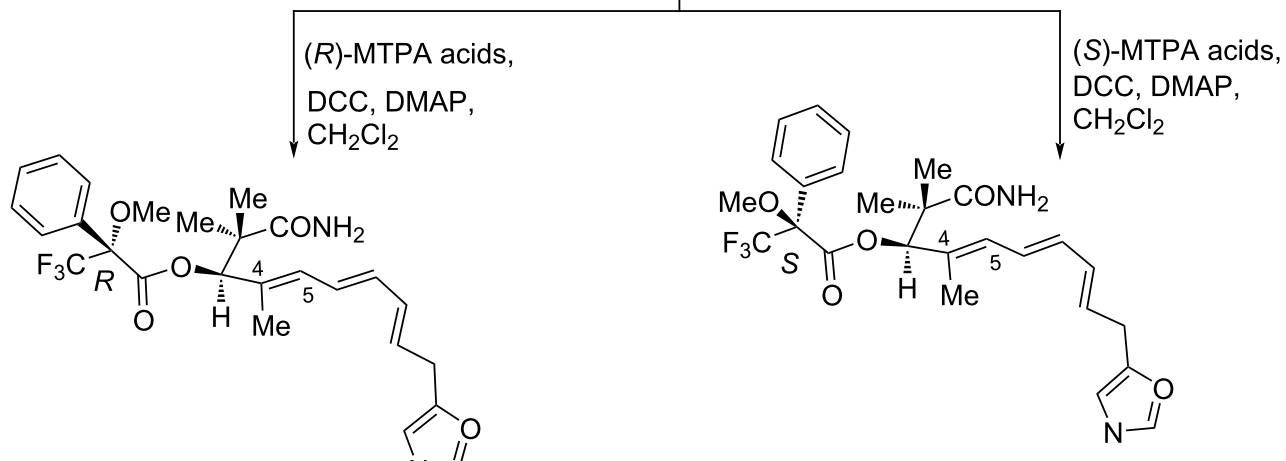

(R)-Mosher ester 106

(S)-Mosher ester 107

Scheme 14: Hale and Hatakeyama's resynthesis of (3R)-inthomycin C (-)-3 Mosher esters.

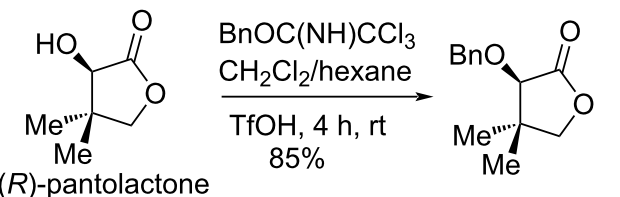

$(R)$-pantolactone $108 \mathrm{a}$

$(+)-109 a$ i) $\mathrm{NH}(\mathrm{Me}) \mathrm{OMe} \cdot \mathrm{HCl}$ $\mathrm{MeMgBr}, \mathrm{THF}, 24 \mathrm{~h} \mathrm{Me}$

ii) TBSCl, imidazole DMF, $24 \mathrm{~h}$, rt ca. $82 \%$ (for 2 steps)<smiles>CC(=O)[C@H](O)C(C)(C)C[O+][Sb]</smiles>

$(+)-110 a$

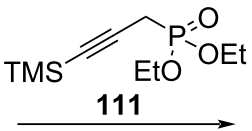

$n$-BuLi, THF, $2 \mathrm{~h}$ $87 \%$ TMS

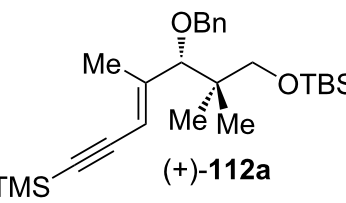

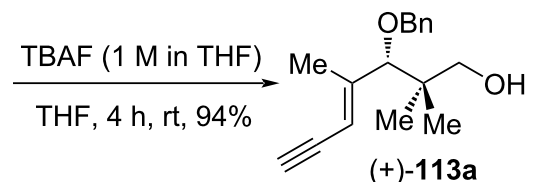

(+)-113a

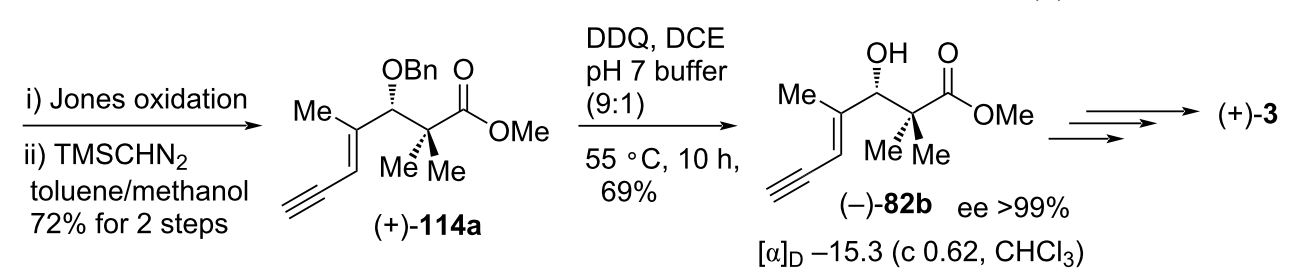<smiles>CC1(C)COC(=O)C1O</smiles>

(S)-pantolactone 108b
DDQ, DCE $\mathrm{pH} 7$ buffer (9:1) $55{ }^{\circ} \mathrm{C}, 10 \mathrm{~h}$, $(-)-114 b$<smiles>C#C/C=C(\C)[C@@H](OCc1ccccc1)C(C)(C)C(=O)OC</smiles>
$71 \%$

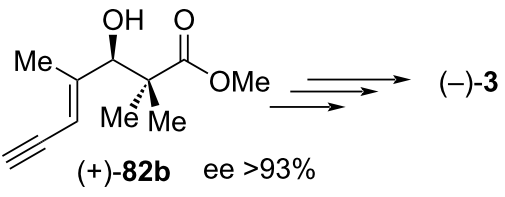

$[\alpha]_{D}+14.7\left(c 0.58, \mathrm{CHCl}_{3}\right)$

Scheme 15: Reddy's formal syntheses of inthomycin C (+)-3 and inthomycin C ((-)-3).

In 2018, Donohoe et al. demonstrated a tin-free, short and efficient total synthesis of inthomycin $\mathrm{C}((-)-3)$ by comprising the three key steps of $\mathrm{C}-\mathrm{C}$ bond-forming reactions: i) a vinylogous Mukaiyama aldol reaction, ii) an olefin cross-metathesis reac- tion, and iii) an asymmetric Mukaiyama-Kiyooka aldol reaction (Scheme 16 and Scheme 17) [8]. The total synthesis was initiated with the preparation of two alkenes precursors ( $r a c$ )118 and 121. The tiglic aldehyde $\mathbf{1 1 5}$ was converted into silyl 

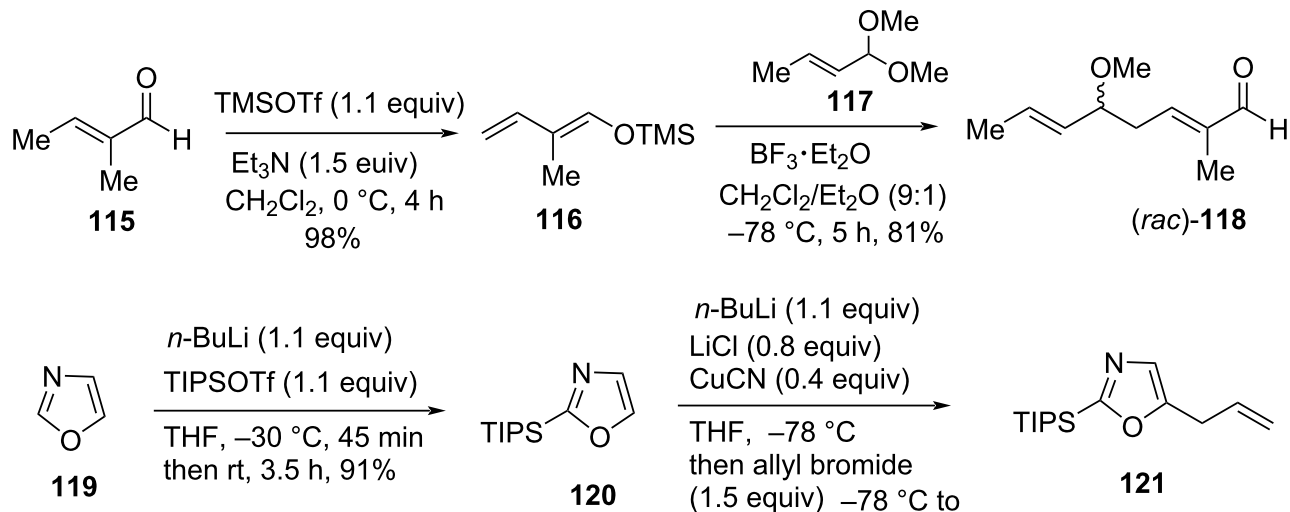

$n$-BuLi (1.1 equiv)

$\mathrm{LiCl}$ (0.8 equiv)

CuCN ( 0.4 equiv)

THF, $-78^{\circ} \mathrm{C}$

then allyl bromide

(1.5 equiv) $-78^{\circ} \mathrm{C}$ to

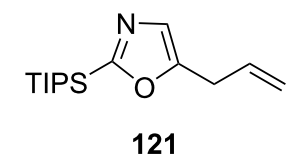

rt, 2 h, $90 \%$<smiles>C=CCc1cnc(C(C)C)o1</smiles><smiles>C/C=C/[C@H](/C=C(\[14CH3])C=O)OC</smiles>

i) $\mathrm{N}$-Ts-L-valine,

$\mathrm{BH}_{3} \cdot \mathrm{THF}$,<smiles>CC(C=O)C=CC=CC=CCc1cnc([SnH])o1</smiles>

$\mathrm{CH}_{2} \mathrm{Cl}_{2}, 0^{\circ} \mathrm{C}$, $20 \mathrm{~min}$

then $\mathrm{rt}, 30 \mathrm{~min}$, then $\mathbf{5 3}$ and $\mathbf{1 2 3}$ $-78{ }^{\circ} \mathrm{C}, 2 \mathrm{~h}$

ii) aq. $\mathrm{HCl} 1 \mathrm{M}$, THF, rt, $1 \mathrm{~h}$, ${ }_{\mathrm{Me}}^{\mathrm{Me}}=\mathrm{OMM}_{\mathrm{S3}}^{\text {OTMS }}$ $63 \%$<smiles>COC(=O)C(C)(C)C(O)/C(C)=C/C=C/C=C/Cc1cnco1</smiles>
$(+)-11$ i) TBSOTf (1.8 equiv) $\mathrm{Et}_{3} \mathrm{~N}$ (2.8 equiv)

ii) $\mathrm{Sc}(\mathrm{OTf})_{3}$ (2.3 equiv) (rac)-122 $0{ }^{\circ} \mathrm{C}$ to $\mathrm{rt}, 21 \mathrm{~h}$, $74 \%$

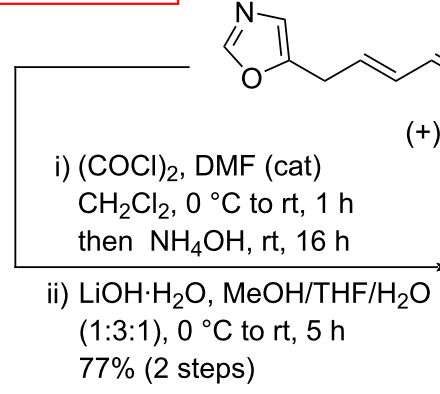

$(+)-76$<smiles>CC=C(C)C(OC(C)=O)C(C)(C)C(=O)O</smiles>

i) $\mathrm{LiOH} \cdot \mathrm{H}_{2} \mathrm{O}$ $\mathrm{MeOH} / \mathrm{THF} / \mathrm{H}_{2} \mathrm{O}$ (1:3:1)

$0{ }^{\circ} \mathrm{C}$ to rt, $12 \mathrm{~h}$

ii) pyridine, $\mathrm{Ac}_{2} \mathrm{O}$ (excess) $0{ }^{\circ} \mathrm{C}$ to rt, $16 \mathrm{~h}, 87 \%$

Scheme 17: Donohoe's total synthesis of inthomycin C ((-)-3).

enol ether 116 followed by treatment with acetal 117 using a vinylogous Mukaiyama aldol reaction to produce the desired aldehyde $(\mathrm{rac}$ )-118 in $\mathbf{8 1 \%}$ yield. Meanwhile, the TIPS protection of oxazole 119 and then subsequent lithiation at the C-5 position and quenching in situ with allyl bromide furnished oxazole derivative $\mathbf{1 2 1}$ in $90 \%$ yield (Scheme 16).
An attempted cross-metathesis reaction of $\mathbf{1 2 1}$ with alkene fragment ( $r a c)-118$ in the presence of Grubbs II (G-II) catalyst under optimized conditions produced ( $\mathrm{rac}$ )-122 in 57\% yield. After exhaustive experimentation, demethoxylation of ( $r a c)-122$ was achieved to produce $(E, E, E)$-aldehyde $\mathbf{1 2 3}$ predominantly in an 8:1 mixture of diastereoisomers. Then, the key aldol reac- 
tion of $\mathbf{1 2 3}$ with silyl enol ether $\mathbf{5 3}$ under optimized Mukaiyama-Kiyooka conditions, followed by TIPS deprotection, afforded adduct $(3 R)-(+)-11$ in $63 \%$ yield and with $94 \%$ ee. Ester hydrolysis followed by acetylation of $(3 R)-(+)-\mathbf{1 1}$ produced acid derivative (+)-76 [50] in 87\% yield. Finally, compound (+)-76 underwent amidation and deacetylation to give an 11.1:1 mixture of geometrical isomers of inthomycin $\mathrm{C}((-)-3)$ in $77 \%$ yield over two steps (Scheme 17) [50]. The (3R) stereochemistry of (-)-3 was confirmed by MTPA ester derivatization, which supports the recent work by Hale and Hatakeyama [57].

Recently, Burton's group developed some efficient and tin-free total syntheses of all three inthomycins A-C $((+)-\mathbf{1},(+)-\mathbf{2}$, and $(-)-3)$ using a Suzuki or Sonogashira cross-coupling of the $(E)$ or $(Z)$-alkenyl iodides $\mathbf{1 3 0}$ with the dienylboronic ester $\mathbf{1 2 8}$ as key step (Schemes 18-22). Initially, $(E)$-pent-2-en-4-yn-1-ol (124) was smoothly converted into the desired bromide derivative 125 [67] in two simple steps. The bromide $\mathbf{1 2 5}$ was then reacted with pre-lithiated oxazole derivative $\mathbf{1 2 0}[68,69]$ under optimized conditions to produce coupled product 126. The selective deprotection of the TMS group of $\mathbf{1 2 6}$ was found to be extremely challenging. The commonly used conditions provided the allene as a major product instead of the desired product. Ultimately, the mono-desilylated product $\mathbf{1 2 7}$ was obtained in $85 \%$ yield by using sodium sulfide in a mixture of THF and water. Next, the zirconium-catalyzed hydroboration of the terminal acetylene in $\mathbf{1 2 7}$ gave $(E, E)-\mathbf{1 2 8}$ in good yield and with complete stereocontrol (Scheme 18).

To accomplish the key Suzuki coupling of dienylboronic ester $\mathbf{1 2 8}$, the necessary alkenyl iodides $(Z)$ - and $(E)$-130 were prepared from the propargyl alcohol (14) in good yields using a four-step sequence such as Negishi's $(Z)$ and $(E)$-stereoselec- tive isomerization of the terminal alkyne followed by iodinolysis $[19,70,71]$, oxidation to the corresponding aldehydes and enantioselective Kiyooka-Mukaiyama aldol reaction followed by TES protection of the resulting alcohols (Scheme 19).

For the synthesis of inthomycin B ((+)-2), a Suzuki coupling reaction between $(E, E)-\mathbf{1 2 8}$ and $(Z)-(+)-\mathbf{1 3 0 a}$ was performed in the presence of palladium(II) acetate, triphenylphosphine, and aqueous sodium carbonate to give (E,E,Z)-triene (+)-131 selectively in $64 \%$ yield. Treatment of triene (+)-131 with HF.pyridine in acetonitrile [22] gave double silyl deprotected triene $(+)-\mathbf{1 3 2}$ which was then converted into inthomycin B ((+)-2) via aminolysis of the corresponding pentaflurophenyl ester (+)-133. The synthetic inthomycin B ((+)-2) showed well-matched spectroscopic properties with that of both natural and synthetic inthomycin B (Scheme 20) $[2,22,43]$.

For the synthesis of inthomycin C ((-)-3), the Suzuki coupling between the dienylboronate $(E, E)-\mathbf{1 2 8}$ and the $(E)-(-)-\mathbf{1 3 0 b}$ was carried out under optimized conditions to produce the $(E, E, E)$-triene derivative (+)-134 in $65 \%$ yield (Scheme 21 ). Then, compound (+)-134 was converted smoothly into inthomycin $\mathrm{C}((-)-3)$ by following the similar sequence of reactions as described for the synthesis of inthomycin B ((+)-2, see Scheme 20).

Having been successful in the synthesis of inthomycins B $((+)-2)$ and $C((-)-3)$, a significant effort was given to the synthesis of inthomycin A ((+)-1). In the beginning, conversion of enyne $\mathbf{1 2 7}$ to the corresponding $(Z, E)$-dienylboronic ester $\mathbf{1 2 8}$ was investigated in the presence of rhodium(I)-catalyzed antiselective hydroboration [72] under several conditions. Unfortunately, the yield of the desired $(Z, E)-\mathbf{1 2 8}$ was found to be poor $(<40 \%)$. Therefore, enyne 127 was selected as a coupling
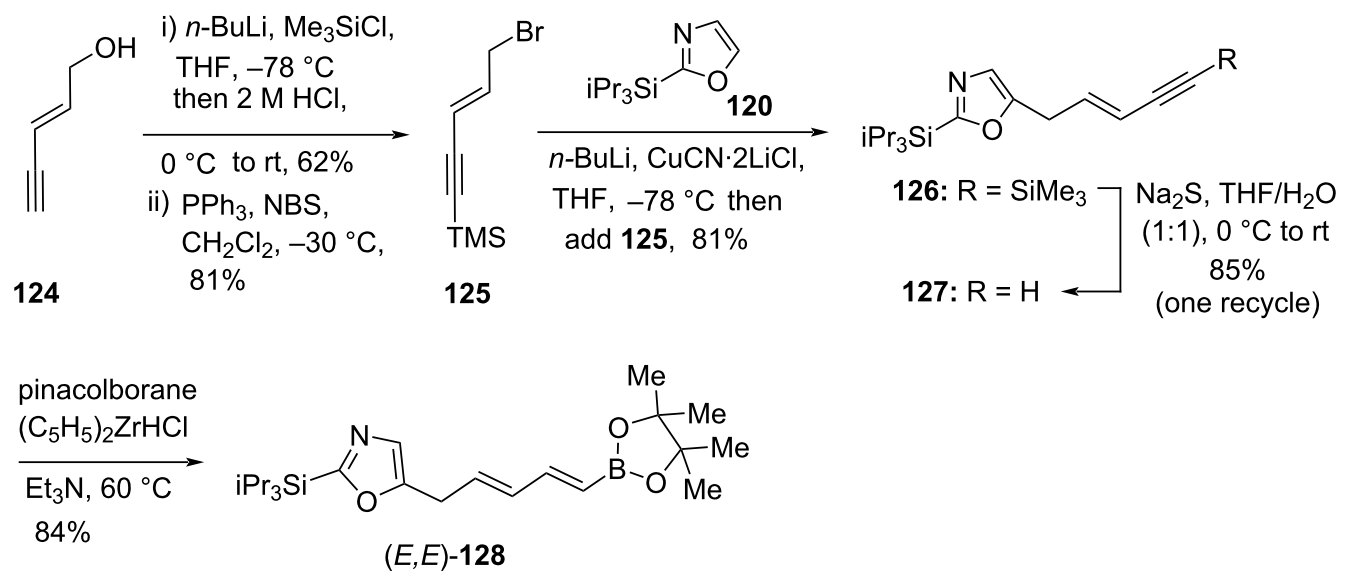


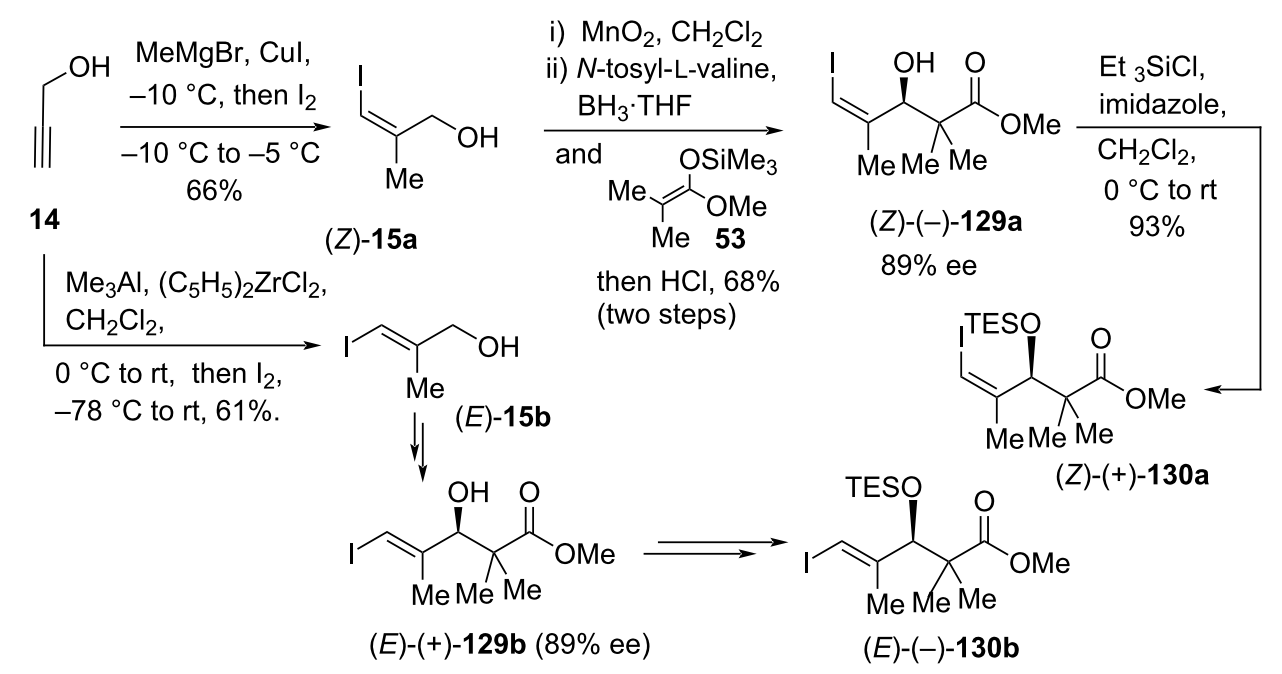

Scheme 19: Synthesis of the alkenyl iodides $(Z)$ - and $(E)-\mathbf{1 3 0}$

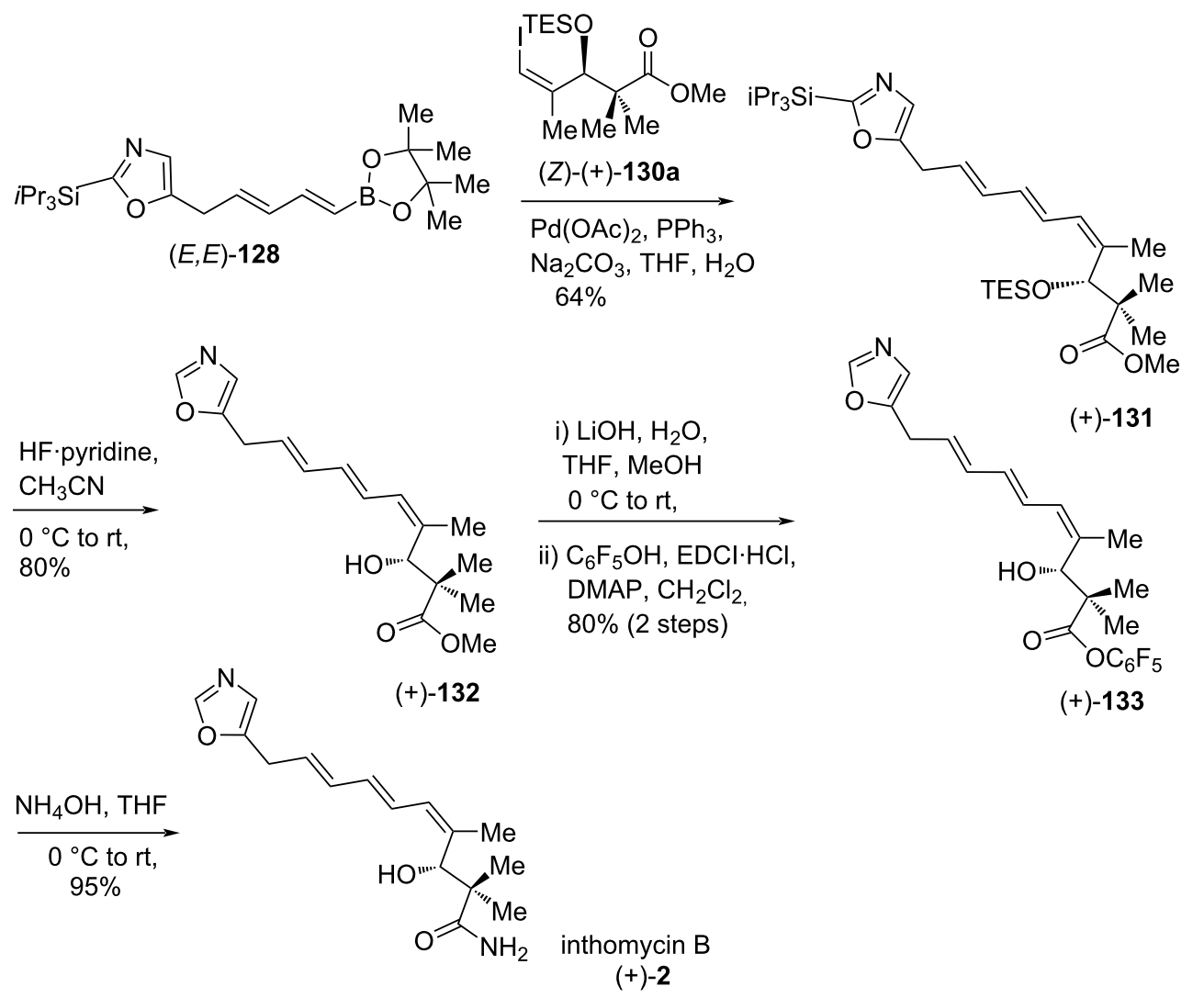

Scheme 20: Burton's total synthesis of inthomycin B ((+)-2).

partner for the key Sonogashira reaction of alkenyl iodide $(Z)-(+)-130 a$ to construct the required $(Z, Z, E)$-triene for completion of the inthomycin A ((+)-1) synthesis. Fortunately, the alkenyl iodide $(Z)-(+)-\mathbf{1 3 0 a}$ coupled smoothly with enyne
127 in the presence of $\mathrm{Pd}\left(\mathrm{PPh}_{3}\right)_{4}, \mathrm{CuI}$, and triethylamine to give (+)-135 in $62 \%$ yield. The double desilylation of compound (+)-135 using HF.pyridine in acetonitrile afforded (-)-136 in $91 \%$ yield. The semi-hydrogenation of $(-)-\mathbf{1 3 6}$ to produce the 


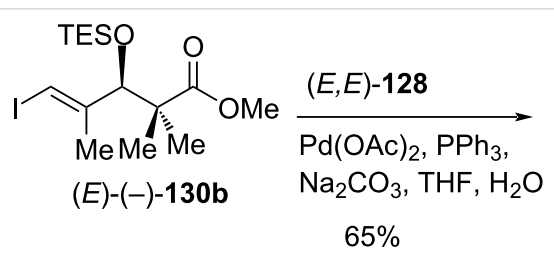<smiles>COC(=O)C(C)(OC)C(OC(F)(F)F)/C(C)=C/C=C/C=C/Cc1cnc(C(C)C)o1</smiles>

$(+)-134$

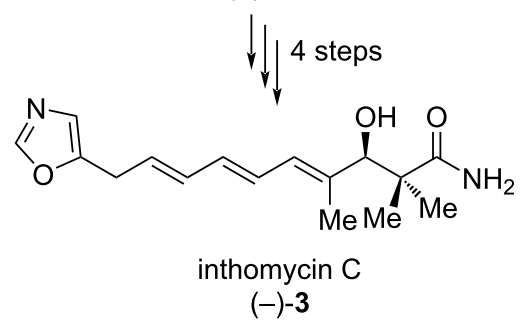

Scheme 21: Burton's total synthesis of inthomycin C ((-)-3).

desired (Z,Z,E)- triene (+)-87 was challenging under a variety of conditions, and eventually, it was achieved by the use of the $\mathrm{Zn}(\mathrm{Cu} / \mathrm{Ag})$ couple in methanol [73]. Finally, the methyl ester $(+)-87$ was readily transformed into inthomycin A $((+)-\mathbf{1})$ via pentaflurorophenyl ester $(+)-\mathbf{1 3 7}$ by the same reaction sequence as described for inthomycin B ((+)-2) in Scheme 20. In this route, the synthetic inthomycin $\mathrm{A}((+)-\mathbf{1})$ was contaminated with a small amount $(<10 \%)$ of inthomycin B ((+)-2, Scheme 22).
Very recently, Kim et al. [24] developed a unified strategy to access all the three isomers of inthomycins A-C ((+)-1, (+)-2, and (-)-3) by using a common intermediate (Z)-143a and an oxazole-derived vinylstannane $\mathbf{2 4}$ or vinyl iodide $\mathbf{4 8}$ (Schemes 23-26). The synthesis started with the preparation of TBS-protected hydroxy pivalic acid 138 [74], following the literature procedure. The acid $\mathbf{1 3 8}$, when submitted to the reaction with oxalyl chloride followed by a CuI-catalyzed nucleophilic alkyne addition of methyl propiolate, provided ynone 139 in $86 \%$ yield<smiles>C#C/C=C/Cc1cnc([SiH2]C(C)C)o1</smiles>

$62 \%$<smiles>COC(=O)C(C)(C)[C@H](O)/C(C)=C/C=C\C=C\Cc1cnco1</smiles>

$(+)-87$

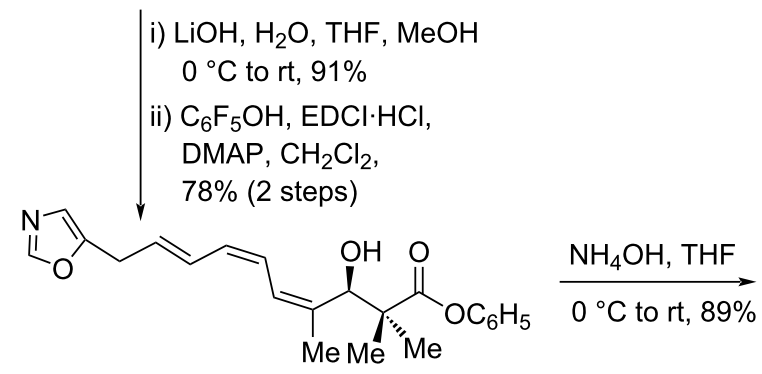

$(+)-137$ 
over two steps. When, compound $\mathbf{1 3 9}$ was treated with (+)diisopinocampheylchloroborane (DIPCl) $[75,76]$ at room temperature and the resulting mixture was processed as in the usual manner using diethanolamine, the expected alcohol (-)-140 was obtained in $93 \%$ ee and $72 \%$ yield. Compound (-)-140 was further transformed to the corresponding Mosher's esters and their NMR and X-ray crystallographic data were well-matched with the $(R)$-stereostructure of $(-)-140$ [77,78]. The hydroxy

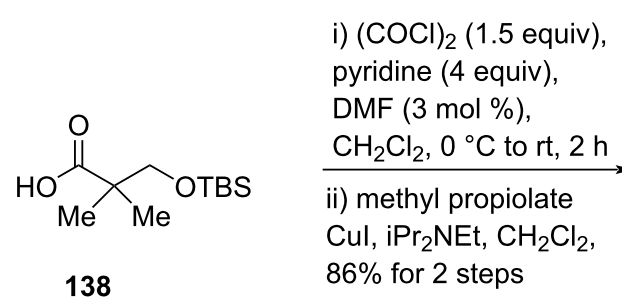

138<smiles>COC(=O)C#CC(O)C(O)(CO)[N+](=O)[O-]</smiles>

$(-)-140$

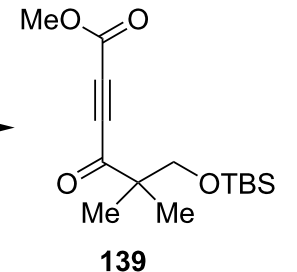

(+)-DIPCI (1.5 equiv), hexane, rt, $16 \mathrm{~h}$; then

diethanolamine (4 equiv)

$0{ }^{\circ} \mathrm{C}$ to rt, $2 \mathrm{~h}, 72 \%$,

$93 \%$ ee

139

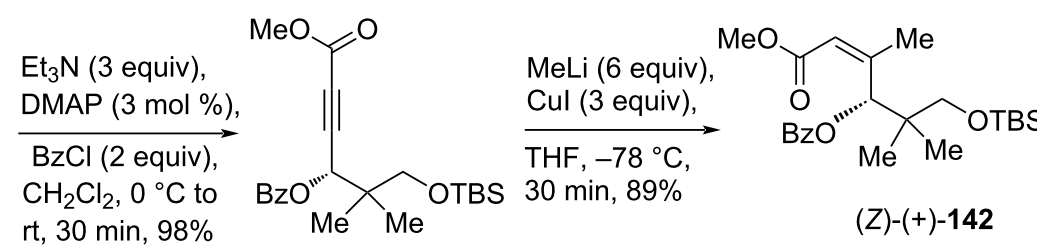

$(-)-141$

i) DIBAL-H ( 2.5 equiv),

THF,$-78^{\circ} \mathrm{C}$ to

$-20^{\circ} \mathrm{C}, 2 \mathrm{~h}, 83 \%$

ii) TPAP $(10 \mathrm{~mol} \%)$, NMO (1.5 equiv), $\mathrm{CH}_{2} \mathrm{Cl}_{2}, \mathrm{rt}, 30 \mathrm{~min}$, $93 \%$

$(Z)-(+)-142$ rt, $30 \mathrm{~min}, 98 \%$

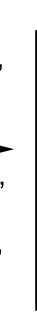

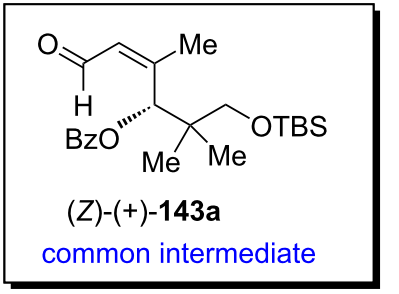

Scheme 23: Synthesis of common intermediate $(Z)-(+)-143 a$.

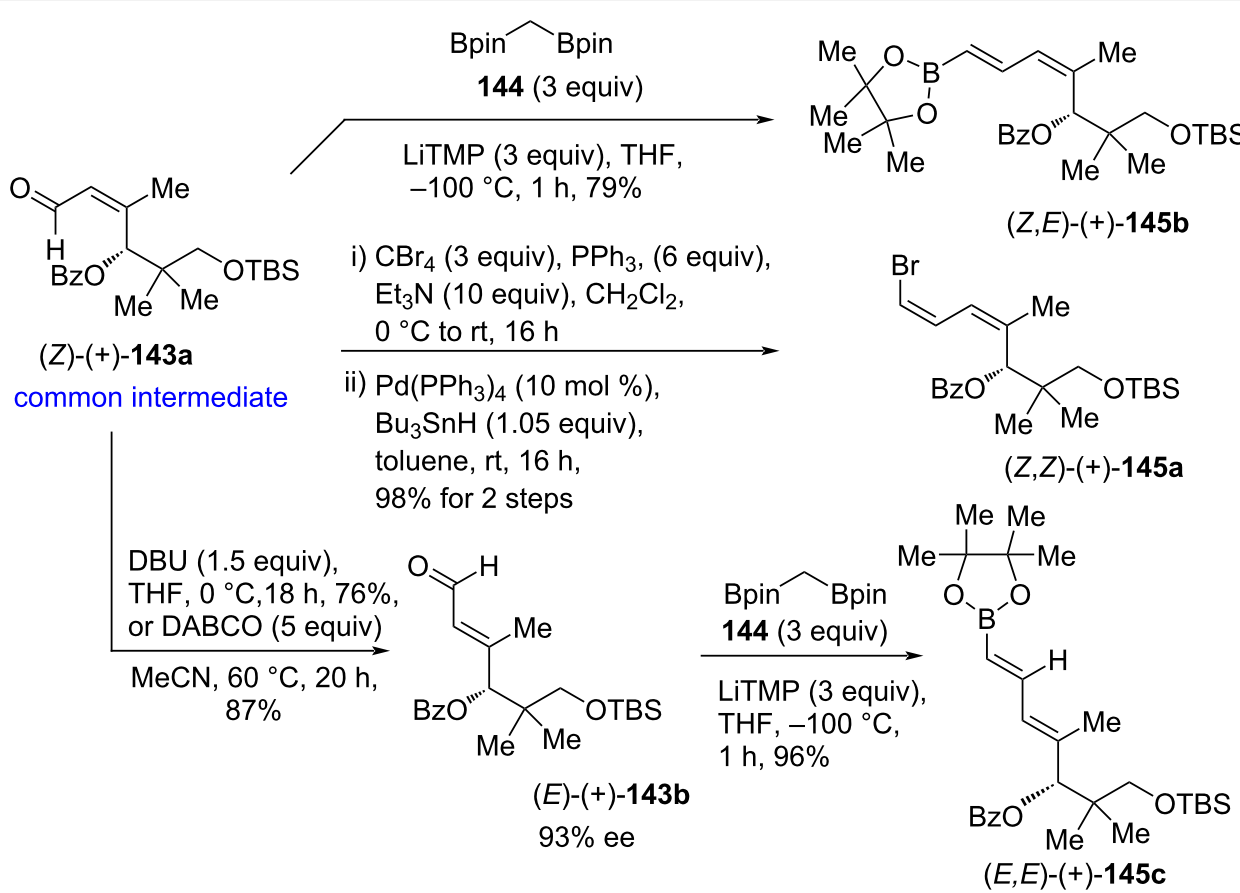

Scheme 24: Synthesis of $(Z)$-and $(E)$-selective fragments (+)-145a-c. 
group of (-)-140 was protected as benzoate to give (-)-141 in good yield. Next, the benzoate-protected ynoate $(-)-\mathbf{1 4 1}$ was converted into aldehyde $(Z)-(+)-\mathbf{1 4 3 a}$ by employing a copper-catalyzed methylation of the alkyne moiety to the corresponding enoate $(Z)-(+)-\mathbf{1 4 2}$ followed by an ester reduction-oxidation sequence using DIBAL-H and TPAP (Scheme 23).

The aldehyde $(Z)-(+)-143 a$ was the common intermediate for the synthesis of $(E)$ - or $(Z)$-selective vinyl boronates or vinyl halides (+)-145 to accomplish total syntheses of all inthomycins A-C ((+)-1, (+)-2 and (-)-3, see Scheme 25 and Scheme 26).
With the key intermediate $(Z)-(+)-\mathbf{1 4 3 a}$ in hand, it was transformed into $(E)$-vinylboronate $(+)$-145b in perfect stereoselectivity by using the recently developed boron-Wittig reaction with bis[(pinacolato)boryl]methane (144) [79]. By applying the Corey-Fuchs dibromoolefination and followed by Pd-catalyzed hydrogenolysis under Uenishi's conditions [80], compound $(Z)-(+)-143$ a delivered the bromodiene $(Z, Z)-(+)-145$ a in good yield and stereoselectivity. Isomerization of $(Z)-(+)-143 a$ to $(E)-$ $(+)-\mathbf{1 4 3 b}$ was carried out successfully using sterically hindered base DBU or DABCO. Treatment of $(E)-(+)-143 b$ with 144 using the boron-Wittig reaction [79] afforded the desired $(E, E)$ vinylboronate $(E, E)-(+)-\mathbf{1 4 5}$ in $96 \%$ yield (Scheme 24$)$. for inthomycin A (+)-1

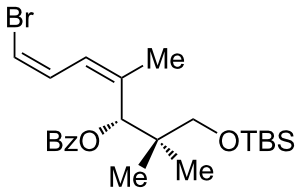

$(Z, Z)-(+)-145 a$

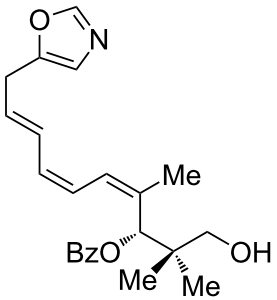

$(+)-147 a$

i) $\mathrm{EDCl} \cdot \mathrm{HCl}$ (1.2 equiv), $\mathrm{NH}_{4} \mathrm{Cl}$ (4 equiv), HOBt (1.2 equiv) $\mathrm{Et}_{3} \mathrm{~N}$ (3 equiv), MeCN, rt, $3 \mathrm{~h}$

ii) $\mathrm{K}_{2} \mathrm{CO}_{3}$ (5 equiv), $\mathrm{MeOH}$, rt, $15 \mathrm{~h}, 43 \%$ for 2 steps

for inthomycin B (+)-2<smiles>CC(=O)OC(/C(C)=C\C=C\B1OC(C)(C)C(C)(C)O1)C(C)(C)C[OH2+]</smiles>

$(Z, E)-(+)-145 b$ (6 equiv),<smiles>CCCCSC=CCc1cnco1</smiles>

24 (2 equiv) PEPPSI-iPr $(6 \mathrm{~mol} \%)$, DMF, $55^{\circ} \mathrm{C}, 36 \mathrm{~h}, 70 \%$.

i) $(\mathrm{COCl})_{2}$ (3 equiv), DMSO

$\mathrm{Et}_{3} \mathrm{~N}$ (13 equiv), $\mathrm{CH}_{2} \mathrm{Cl}_{2}$, $-78^{\circ} \mathrm{C}$, to rt, $40 \mathrm{~min}$

ii) $\mathrm{NaClO}_{2}$ (3 equiv), $\mathrm{NaH}_{2} \mathrm{PO}_{4}$ (3 equiv), 2-methyl-2-butene (37 equiv), $t-\mathrm{BuOH} /$ water (1:1), $0{ }^{\circ} \mathrm{C}, 30 \mathrm{~min}, 81 \%$ for 2 steps

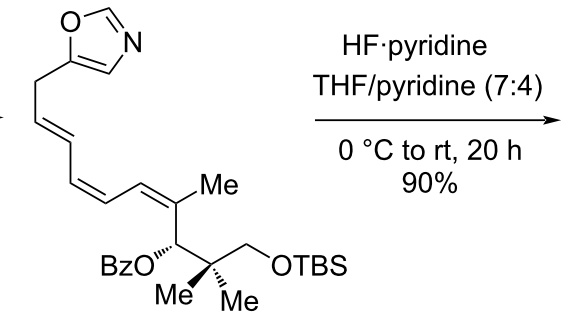

$(+)-146 a$<smiles>C/C=C\C=C/C=C(/C)C(=O)C(C)(C)C(=O)O</smiles>

(+)-148a<smiles>C/C(=C/C=C\C=C/Cc1cnco1)C(O)C(C)(C)C(N)=O</smiles>

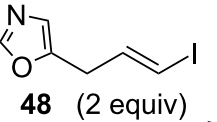

$\mathrm{Ag}_{2} \mathrm{O}$ (3.7 equiv), $\mathrm{Pd}(\mathrm{PPh})_{4}(13 \mathrm{~mol} \%)$, $\mathrm{THF} / \mathrm{H}_{2} \mathrm{O}(9: 1)$, rt, $5 \mathrm{~min}, 85 \%$<smiles>[R6]OC(/C(C)=C\C=C\C=C\Cc1cnco1)C(C)(C)C[OH+]CC</smiles>

$(+)-146 b$

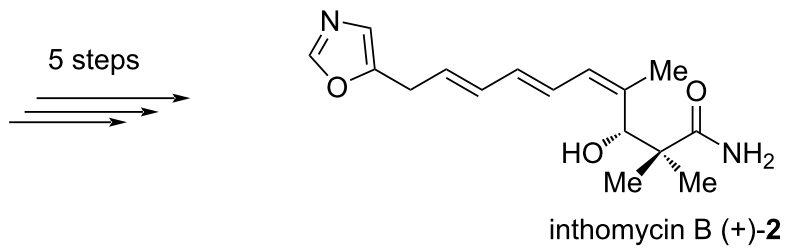

Scheme 25: Kim's total synthesis of inthomycins A (+)-1 and B (+)-2 
Followed by the successful access to $(Z)$ - and $(E)$-selective isomers of (+)-145a-c, further exploration to the incorporation of a triene unit of inthomycins was investigated. The PEPPSIiPr-catalyzed [58] Stille cross-coupling between vinyl bromide $(Z, Z)-(+)-145 a$ and $(E)$-vinylstannane 24 [43] proceeded without significant isomerization to give $(4 Z, 6 Z, 8 E)$-triene (+)-146a, a subunit of inthomycin A $((+)-1)$. Meanwhile, the Suzuki-Miyaura coupling of vinylboronate $(Z, E)-(+)-\mathbf{1 4 5} \mathbf{b}$ with the known $(E)$-oxazole iodide 48 [43] was performed successfully to afford geometrically pure $(4 Z, 6 E, 8 E)$-triene (+)-146b in $85 \%$ yield following the synthesis of inthomycin B ((+)-2). Careful deprotection of silyl ether of (+)-146a with HF.pyridine in THF/pyridine delivered alcohol (+)-147a. Next, the Swern oxidation of the resulting alcohol $(+)-\mathbf{1 4 7}$ a followed by Pinnick oxidation afforded the acid (+)-148a. Finally, the EDCl-mediated amidation of unstable acid $(+)-148$ a followed by debenzoylation produced inthomycin A $((+)-\mathbf{1})$. Similarly, compound (+)-146b was converted into inthomycin B ((+)-2) (Scheme 25).

To complete the total synthesis of inthomycin $C((-)-3)$, a cross-coupling between $(E, E)-(+)-\mathbf{1 4 5 c}$ and vinyl iodide $\mathbf{4 8}$ was carried out to produce $(4 E, 6 E, 8 E)$-triene $(+)-146 \mathrm{c}$ in $82 \%$ yield. Utilizing the same sequence as applied to the synthesis of inthomycin As $((+)-1)$ and B $((+)-2)$ from $(+)-146 a$ and $(+)-\mathbf{1 4 6 b}$, respectively (see Scheme 25), the triene (+)-146c was successfully converted into an 8:1 mixture of inthomycin $\mathrm{C}$ $((-)-3)$ and another minor isomer in good overall yield after the final step (Scheme 26). The spectroscopic data and specific rotation values of the three inthomycins A-C ((+)-1, (+)-2, and $(-)-3)$ were consistent with those reported previously $[8,23,57]$. The absolute configurations of inthomycins A-C ((+)-1, (+)-2, and (-)-3) were reconfirmed as $3 R$ by assigning the $(R)$-stereochemical descriptor for the common intermediate (-)-140, which supports the recent work of Hale and Hatakeyama [57].

\section{Conclusion}

This review highlighted reports on the various synthetic efforts for both the formal and total synthesis of racemic and enantiopure inthomycins A-C (1-3). These compounds have three key structural features: an oxazole ring, a triene system, and an amide moiety with a chiral, hydroxylated carbon at the $\beta$-position. These interesting structures accompanied by their promising biological activities and the lack of natural sources have made inthomycins an attractive target in the synthetic organic community to work intensively in this area. The synthesis of simple looking inthomycins is challenging due to the unusually interposed functional groups and isomerizable double bonds in the conjugated triene moiety. Various stereoselective cross-coupling reactions such as Stille, Suzuki, or Sonogashira or
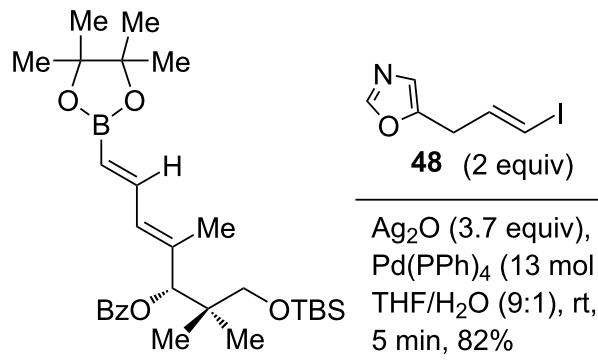

$\mathrm{Ag}_{2} \mathrm{O}$ (3.7 equiv), $\mathrm{Pd}(\mathrm{PPh})_{4}(13 \mathrm{~mol} \%)$ $\mathrm{THF} / \mathrm{H}_{2} \mathrm{O}(9: 1)$, rt, $5 \mathrm{~min}, 82 \%$

$(E, E)-(+)-145 c$

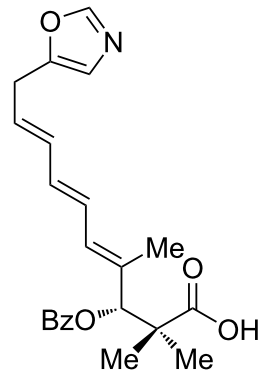

$(+)-148 c$ i) $\mathrm{EDCl} \cdot \mathrm{HCl}$ (1.2 equiv), $\mathrm{NH}_{4} \mathrm{Cl}$ (4 equiv), $\mathrm{HOBt}$ (1.2 equiv),

$\mathrm{Et}_{3} \mathrm{~N}$ (3 equiv), MeCN, $\mathrm{rt}, 3 \mathrm{~h}, 52 \%$

ii) $\mathrm{K}_{2} \mathrm{CO}_{3}$ (5 equiv),

$\mathrm{MeOH}, \mathrm{rt}, 5 \mathrm{~h}, 98 \%$

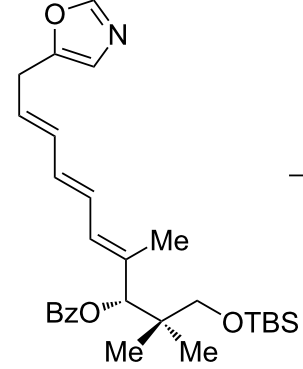

$(+)-146 c$

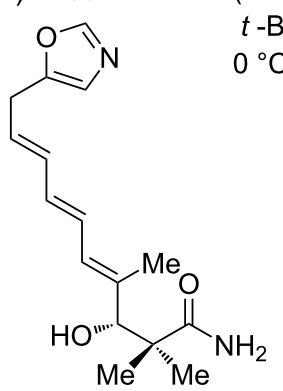

inthomycin C (-)-3

[8:1 mixture in favor of (-)-3] 
Suzuki-Miyaura have been utilized to construct the geometrically distinctive polyene systems of inthomycins A-C (1-3). The elegant work of R. J. K. Taylor [21,43], Ryu [50], Donohoe [57], and Burton [23] demonstrated the power of the Mukaiyama-Kiyooka aldol reactions to install the asymmetric center of inthomycins. Alternatively, Hatakeyama and Kim's groups employed an asymmetric $\beta$-lactone synthesis and an asymmetric ynone reduction protocol for the construction of the stereogenic center of inthomycins, respectively [22,24]. Despite these recent advances, the development of novel methods for the regio- and stereocontrolled synthesis of inthomycins, inthomycin-embedded natural products, and their synthetic analogues with better biological outcomes is of strategic importance and being continued for further discovery.

\section{Funding}

The author gratefully acknowledges the financial assistance of the Science \& Engineering Research Board (TAR/2018/ 000904), New Delhi, India.

\section{ORCID ${ }^{\circledR}$ iDs}

Bidyut Kumar Senapati - https://orcid.org/0000-0002-2185-8896

\section{References}

1. Omura, S.; Tanaka, Y.; Kanaya, I.; Shinose, M.; Takahashi, Y. J. Antibiot. 1990, 43, 1034-1036. doi:10.7164/antibiotics.43.1034

2. Henkel, T.; Zeeck, A. Liebigs Ann. Chem. 1991, 367-373. doi:10.1002/jlac.199119910164

3. Shiomi, K.; Arai, N.; Shinose, M.; Takahashi, Y.; Yoshida, H.; Iwabuchi, J.; Tanaka, Y.; Omura, S. J. Antibiot. 1995, 48, 714-719. doi:10.7164/antibiotics.48.714

4. Tanaka, Y.; Kanaya, I.; Takahashi, Y.; Shinose, M.; Tanaka, H.; Omura, S. J. Antibiot. 1993, 46, 1208-1213. doi:10.7164/antibiotics.46.1208

5. Ōmura, S. Gene 1992, 115, 141-149 doi:10.1016/0378-1119(92)90552-z

6. Kawada, M.; Inoue, H.; Usami, I.; Ikeda, D. Cancer Sci. 2009, 100, 150-157. doi:10.1111/j.1349-7006.2008.00996.x

7. Kawada, M.; Yoshimoto, Y.; Minamiguchi, K.; Kumagai, H.; Someno, T.; Masuda, T.; Ishizuka, M.; Ikeda, D. Anticancer Res. 2004, 24, 1561-1568.

8. Balcells, S.; Haughey, M. B.; Walker, J. C. L.; Josa-Culleré, L.; Towers, C.; Donohoe, T. J. Org. Lett. 2018, 20, 3583-3586. doi:10.1021/acs.orglett.8b01370

9. Takahashi, K.; Kawabata, M.; Uemura, D.; Iwadare, S.; Mitomo, R.; Nakano, F.; Matsuzaki, A. Tetrahedron Lett. 1985, 26, 1077-1078. doi:10.1016/s0040-4039(00)98516-2

10. Kawai, S.; Kawabata, G.; Kobayashi, A.; Kawazu, K. Agric. Biol. Chem. 1989, 53, 1127-1133. doi:10.1271/bbb1961.53.1127

11. Mori, T.; Takahashi, K.; Kashiwabara, M.; Uemura, D.; Katayama, C. Iwadare, S.; Shizuri, Y.; Mitomo, R.; Nakano, F.; Matsuzaki, A. Tetrahedron Lett. 1985, 26, 1073-1076. doi:10.1016/s0040-4039(00)98515-0
12. Kanzaki, H.; Wada, K.-i.; Nitoda, T.; Kawazu, K. Biosci., Biotechnol., Biochem. 1998, 62, 438-442. doi:10.1271/bbb.62.438

13. Ryu, G.; Hwang, S.; Kim, S.-K. J. Antibiot. 1997, 50, 1064-1066. doi:10.7164/antibiotics.50.1064

14. Ryu, G.; Kim, S.-K. J. Antibiot. 1999, 52, 193-197. doi:10.7164/antibiotics.52.193

15. Ogura, M.; Nakayama, H.; Furihata, K.; Shimazu, A.; Seto, H.; Otake, N. J. Antibiot. 1985, 38, 669-673. doi:10.7164/antibiotics.38.669

16. Otani, T.; Yoshida, K.; Kubota, H.; Kawai, S.; Ito, S.; Hori, H.; Ishiyama, T.; Oki, T. J. Antibiot. 2000, 53, 1397-1400. doi:10.7164/antibiotics.53.1397

17. Ishihara, J.; Hatakeyama, S. Chem. Rec. 2014, 14, 663-677. doi:10.1002/tcr.201402009

18. Lee, V. Org. Biomol. Chem. 2019, 17, 9095-9123. doi:10.1039/c9ob01602c

19. Hénaff, N.; Whiting, A. Org. Lett. 1999, 1, 1137-1139. doi:10.1021/ol990967b

20. Hénaff, N.; Whiting, A. Tetrahedron 2000, 56, 5193-5204. doi:10.1016/s0040-4020(00)00182-4

21. Webb, M. R.; Addie, M. S.; Crawforth, C. M.; Dale, J. W.; Franci, X.; Pizzonero, M.; Donald, C.; Taylor, R. J. K. Tetrahedron 2008, 64, 4778-4791. doi:10.1016/j.tet.2008.01.116

22. Yoshino, M.; Eto, K.; Takahashi, K.; Ishihara, J.; Hatakeyama, S. Org. Biomol. Chem. 2012, 10, 8164-8174. doi:10.1039/c2ob26084k

23. Kumar, M.; Bromhead, L.; Anderson, Z.; Overy, A.; Burton, J. W. Chem. - Eur. J. 2018, 24, 16753-16756. doi:10.1002/chem.201803794

24. Kim, J. H.; Song, Y.; Kim, M. J.; Kim, S. J. Org. Chem. 2020, 85, 4795-4806. doi:10.1021/acs.joc.0c00017

25. Evans, D. A.; Vogel, E.; Nelson, J. V. J. Am. Chem. Soc. 1979, 101, 6120-6123. doi:10.1021/ja00514a045

26. Evans, D. A.; Nelson, J. V.; Vogel, E.; Taber, T. R. J. Am. Chem. Soc. 1981, 103, 3099-3111. doi:10.1021/ja00401a031

27. Evans, D. A.; Bartroli, J.; Shih, T. L. J. Am. Chem. Soc. 1981, 103 , 2127-2129. doi:10.1021/ja00398a058

28. Gage, J. R.; Evans, D. A. Org. Synth. 1990, 68, 83. doi:10.15227/orgsyn.068.0083

29. Kiyooka, S.-i.; Kira, H.; Hena, M. A. Tetrahedron Lett. 1996, 37, 2597-2600. doi:10.1016/0040-4039(96)00379-6

30. Parmee, E. R.; Hong, Y.; Tempkin, O.; Masamune, S. Tetrahedron Lett. 1992, 33, 1729-1732. doi:10.1016/s0040-4039(00)91717-9

31. Hoffmann, R. W.; Landmann, B. Chem. Ber. 1986, 119, 2013-2024. doi:10.1002/cber.19861190622

32. Hunt, A. R.; Stewart, S. K.; Whiting, A. Tetrahedron Lett. 1993, 34, 3599-3602. doi:10.1016/s0040-4039(00)73646-x

33. Stewart, S. K.; Whiting, A. J. Organomet. Chem. 1994, 482, 293-300. doi:10.1016/0022-328x(94)88213-4

34. Stewart, S. K.; Whiting, A. Tetrahedron Lett. 1995, 36, 3925-3928. doi:10.1016/0040-4039(95)00643-q

35. Stewart, S. K.; Whiting, A. Tetrahedron Lett. 1995, 36, 3929-3932. doi:10.1016/0040-4039(95)00644-r

36. Bulger, P. G.; Moloney, M. G.; Trippier, P. C. Synlett 2002, 1871-1873. doi:10.1055/s-2002-34905

37. Lenz, R.; Ley, S. V. J. Chem. Soc., Perkin Trans. 1 1997, 3291-3292. doi:10.1039/a707339i

38. Takai, K.; Nitta, K.; Utimoto, K. J. Am. Chem. Soc. 1986, 108, 7408-7410. doi:10.1021/ja00283a046 
39. Bulger, P. G.; Moloney, M. G.; Trippier, P. C. Org. Biomol. Chem. 2003, 1, 3726-3737. doi:10.1039/b306925g

40. Stork, G.; Zhao, K. Tetrahedron Lett. 1989, 30, 2173-2174. doi:10.1016/s0040-4039(00)99640-0

41. Uenishi, J.; Kawahama, R.; Shiga, Y.; Yonemitsu, O.; Tsuji, J. Tetrahedron Lett. 1996, 37, 6759-6762. doi:10.1016/s0040-4039(96)01461-x

42. Duboudin, J. G.; Jousseaume, B.; Bonakdar, A.; Saux, A. J. Organomet. Chem. 1979, 168, 227-232. doi:10.1016/s0022-328x(00)83278-7

43. Webb, M. R.; Donald, C.; Taylor, R. J. K. Tetrahedron Lett. 2006, 47, 549-552. doi:10.1016/j.tetlet.2005.11.042

44. Vedejs, E.; Luchetta, L. M. J. Org. Chem. 1999, 64, 1011-1014. doi:10.1021/j0981367d

45. Kende, A. S.; Kawamura, K.; DeVita, R. J. J. Am. Chem. Soc. 1990, 112, 4070-4072. doi:10.1021/ja00166a072

46. Wender, P. A.; Sieburth, S. McN.; Petraitis, J. J.; Singh, S. K. Tetrahedron 1981, 37, 3967-3975. doi:10.1016/s0040-4020(01)93271-5

47. Ley, S. V.; Norman, J.; Griffith, W. P.; Marsden, S. P. Synthesis 1994, 639-666. doi:10.1055/s-1994-25538

48. Franci, X.; Martina, S. L. X.; McGrady, J. E.; Webb, M. R.; Donald, C.; Taylor, R. J. K. Tetrahedron Lett. 2003, 44, 7735-7740. doi:10.1016/j.tetlet.2003.08.095

49. Ando, K. Tetrahedron Lett. 1995, 36, 4105-4108. doi:10.1016/0040-4039(95)00726-s

50. Senapati, B. K.; Gao, L.; Lee, S. I.; Hwang, G.-S.; Ryu, D. H. Org. Lett. 2010, 12, 5088-5091. doi:10.1021/ol102234k

51. Mee, S. P. H.; Lee, V.; Baldwin, J. E. Angew. Chem., Int. Ed. 2004, 43 , 1132-1136. doi:10.1002/anie.200352979

52. Mee, S. P. H.; Lee, V.; Baldwin, J. E. Chem. - Eur. J. 2005, 11, 3294-3308. doi:10.1002/chem.200401162

53. Nelson, S. G.; Wan, Z. Org. Lett. 2000, 2, 1883-1886. doi:10.1021/ol005968e

54. Nelson, S. G.; Zhu, C.; Shen, X. J. Am. Chem. Soc. 2004, 126, 14-15. doi:10.1021/ja0391208

55. Zhu, C.; Shen, X.; Nelson, S. G. J. Am. Chem. Soc. 2004, 126, 5352-5353. doi:10.1021/ja0492900

56. Onyango, E. O.; Tsurumoto, J.; Imai, N.; Takahashi, K.; Ishihara, J.; Hatakeyama, S. Angew. Chem., Int. Ed. 2007, 46, 6703-6705. doi:10.1002/anie.200702229

57. Hale, K. J.; Hatakeyama, S.; Urabe, F.; Ishihara, J.; Manaviazar, S.; Grabski, M.; Maczka, M. Org. Lett. 2014, 16, 3536-3539. doi:10.1021/ol501484t

58. Souris, C.; Frébault, F.; Patel, A.; Audisio, D.; Houk, K. N.; Maulide, N. Org. Lett. 2013, 15, 3242-3245. doi:10.1021/ol401226y

59. García-García, P.; Lay, F.; García-García, P.; Rabalakos, C.; List, B. Angew. Chem., Int. Ed. 2009, 48, 4363-4366. doi:10.1002/anie.200901768

60. Hale, K. J.; Grabski, M.; Manaviazar, S.; Maczka, M. Org. Lett. 2014, 16, 1164-1167. doi:10.1021/ol5000499

61. Frantz, D. E.; Fässler, R.; Carreira, E. M. J. Am. Chem. Soc. 2000, 122, 1806-1807. doi:10.1021/ja993838z

62. Boyall, D.; López, F.; Sasaki, H.; Frantz, D.; Carreira, E. M. Org. Lett. 2000, 2, 4233-4236. doi:10.1021/ol006791r

63. Boyall, D.; Frantz, D. E.; Carreira, E. M. Org. Lett. 2002, 4, 2605-2606. doi:10.1021/ol026282k

64. Andrus, M. B.; Lepore, S. D.; Sclafani, J. A. Tetrahedron Lett. 1997, 38, 4043-4046. doi:10.1016/s0040-4039(97)00861-7
65. Sharpless, K. B.; Amberg, W.; Bennani, Y. L.; Crispino, G. A.; Hartung, J.; Jeong, K. S.; Kwong, H. L.; Morikawa, K.; Wang, Z. M. J. Org. Chem. 1992, 57, 2768-2771. doi:10.1021/jo00036a003

66. Athawale, P. R.; Kashinath, K.; Reddy, D. S. ChemistrySelect 2016, 1 , 495-497. doi:10.1002/slct.201600128

67. Nicolaou, K. C.; Veale, C. A.; Webber, S. E.; Katerinopoulos, H. J. Am. Chem. Soc. 1985, 107, 7515-7518. doi:10.1021/ja00311a048

68. Miller, R. A.; Smith, R. M.; Karady, S.; Reamer, R. A. Tetrahedron Lett. 2002, 43, 935-938. doi:10.1016/s0040-4039(01)02342-5

69. Miller, R. A.; Smith, R. M.; Marcune, B. J. Org. Chem. 2005, 70, 9074-9076. doi:10.1021/jo051490m

70. Kotora, M.; Negishi, E.-i. Synthesis 1997, 121-128. doi:10.1055/s-1997-1513

71. Wang, G.; Negishi, E.-i. Eur. J. Org. Chem. 2009, 1679-1682. doi:10.1002/ejoc.200801188

72. Ohmura, T.; Yamamoto, Y.; Miyaura, N. J. Am. Chem. Soc. 2000, 122, 4990-4991. doi:10.1021/ja0002823

73. Boland, W.; Schroer, N.; Sieler, C.; Feigel, M. Helv. Chim. Acta 1987, 70, 1025-1040. doi:10.1002/hlca.19870700415

74. Hale, K. J.; Xiong, Z.; Wang, L.; Manaviazar, S.; Mackle, R. Org. Lett. 2015, 17, 198-201. doi:10.1021/ol503222j

75. Brown, H. C.; Chandrasekharan, J.; Ramachandran, P. V. J. Am. Chem. Soc. 1988, 110, 1539-1546. doi:10.1021/ja00213a030

76. Ramachandran, P. V.; Teodorovic, A. V.; Rangaishenvi, M. V.; Brown, H. C. J. Org. Chem. 1992, 57, 2379-2386. doi:10.1021/jo00034a034

77. Ohtani, I.; Kusumi, T.; Kashman, Y.; Kakisawa, H. J. Am. Chem. Soc. 1991, 113, 4092-4096. doi:10.1021/ja00011a006

78. Hoye, T. R.; Jeffrey, C. S.; Shao, F. Nat. Protoc. 2007, 2, 2451-2458. doi:10.1038/nprot.2007.354

79. Coombs, J. R.; Zhang, L.; Morken, J. P. Org. Lett. 2015, 17, 1708-1711. doi:10.1021/acs.orglett.5b00480

80. Uenishi, J.; Kawahama, R.; Yonemitsu, O.; Tsuji, J. J. Org. Chem. 1998, 63, 8965-8975. doi:10.1021/j09812781

\section{License and Terms}

This is an Open Access article under the terms of the Creative Commons Attribution License (https://creativecommons.org/licenses/by/4.0). Please note that the reuse, redistribution and reproduction in particular requires that the author(s) and source are credited and that individual graphics may be subject to special legal provisions.

The license is subject to the Beilstein Journal of Organic Chemistry terms and conditions: (https://www.beilstein-journals.org/bjoc/terms)

The definitive version of this article is the electronic one which can be found at: https://doi.org/10.3762/bjoc.17.7 